\title{
Flagella-Driven Motility of Bacteria
}

\author{
Shuichi Nakamura ${ }^{1}$ and Tohru Minamino ${ }^{2, *}$ \\ 1 Department of Applied Physics, Graduate School of Engineering, Tohoku University, 6-6-05 Aoba, Aoba-ku, \\ Sendai 980-8579, Japan \\ 2 Graduate School of Frontier Biosciences, Osaka University, 1-3 Yamadaoka, Suita, Osaka 565-0871, Japan \\ * Correspondence: tohru@fbs.osaka-u.ac.jp; Tel.: +81-6-6879-4625
}

Received: 27 June 2019; Accepted: 12 July 2019; Published: 14 July 2019

\begin{abstract}
The bacterial flagellum is a helical filamentous organelle responsible for motility. In bacterial species possessing flagella at the cell exterior, the long helical flagellar filament acts as a molecular screw to generate thrust. Meanwhile, the flagella of spirochetes reside within the periplasmic space and not only act as a cytoskeleton to determine the helicity of the cell body, but also rotate or undulate the helical cell body for propulsion. Despite structural diversity of the flagella among bacterial species, flagellated bacteria share a common rotary nanomachine, namely the flagellar motor, which is located at the base of the filament. The flagellar motor is composed of a rotor ring complex and multiple transmembrane stator units and converts the ion flux through an ion channel of each stator unit into the mechanical work required for motor rotation. Intracellular chemotactic signaling pathways regulate the direction of flagella-driven motility in response to changes in the environments, allowing bacteria to migrate towards more desirable environments for their survival. Recent experimental and theoretical studies have been deepening our understanding of the molecular mechanisms of the flagellar motor. In this review article, we describe the current understanding of the structure and dynamics of the bacterial flagellum.
\end{abstract}

Keywords: bacterial flagellum; chemotaxis; ion motive force; ion channel; mechanochemical coupling; molecular motor; motility; torque generation

\section{Introduction}

Bacterial motility is an extremely intriguing topic from various scientific aspects. For example, motility can be a crucial virulence attribute for pathogenic bacteria, such as Salmonella enterica (hereafter referred to Salmonella) and Helicobacter pylori $[1,2]$. Bacterial motility also plays a significant role in mutualistic symbioses [3,4]. Furthermore, motile bacteria are also a representative example for understanding the underlying physical principles that form the basis of energy conversion, force generation and mechanochemical coupling mechanisms [5]. Active motilities of bacteria are represented by movement in liquid (e.g., swimming motility in Escherichia coli and Salmonella) and on solid surfaces (e.g., flagella-driven swarming motility in Proteus mirabilis and Vibrio parahaemolyticus, gliding motility in Mycoplasma mobile, and twitching motility in Pseudomonas aeruginosa), and passive motility is typically actin-based locomotion (e.g., Listeria monocytogenes and Shigella spp.) [6]. Since bacterial motility varies among bacterial species, bacteria utilize their own motility system optimized for their habitats.

E. coli and Salmonella use flagella viewable from the cell exterior as a thin, long, helical filament (Figure 1a). On the other hand, the flagella of spirochetes reside within the periplasmic space, and so they are called periplasmic flagella [7]. Whether the bacterial flagella are exposed to the cell exterior or are hidden within the cell body, the flagellum is divided into three structural parts: the basal body as a rotary motor, the hook as a universal joint and the filament as a molecular screw in common (Figure $1 \mathrm{~b}$ ), and flagellar formation and function involves more than 60 genes [8-10]. 


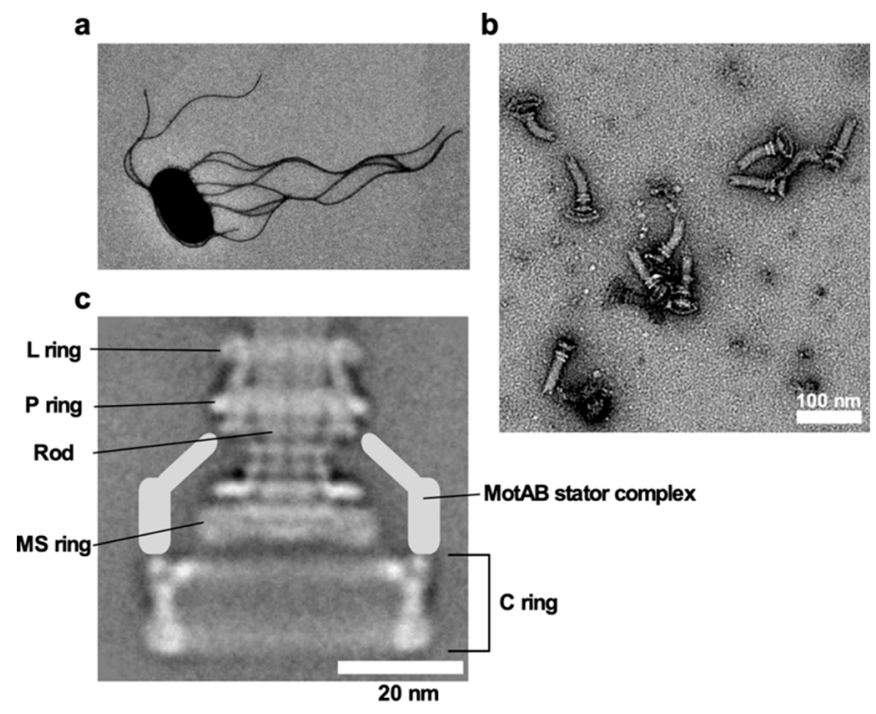

Figure 1. Salmonella flagellum. (a) Electron micrograph of Salmonella cell. The micrograph was taken at a magnification of $\times 1200$. (b) Electron micrograph of hook-basal bodies isolated from Salmonella cells. (c) CryoEM image of purified basal body. Purified basal body consists of the L, P, MS and C rings and the rod. A dozen MotAB complex are associated with the basal body to act as a stator unit in the motor but is gone during purification.

The bacterial flagellar motor is powered by the transmembrane electrochemical gradient of ions, namely ion motive force (IMF) and rotates the flagellar filament to generate thrust to propel the cell body. The maximum motor speed reaches 300 revolutions per second in E. coli and Salmonella [11] and 1700 revolutions per second in a marine bacterium Vibrio alginolyticus [12]. Thus, the rotational speed of the flagellar motor is much faster than that of a manufactured car engine such as formula one car. The flagellar motor is composed of a rotor and multiple stator units. Each stator unit acts as a transmembrane ion channel to conduct cations such as protons $\left(\mathrm{H}^{+}\right)$or sodium ions $\left(\mathrm{Na}^{+}\right)$and applies force on the rotor [13,14].

The flagellar motors of E. coli and Salmonella rotate in both counterclockwise (CCW) and clockwise (CW) without changing the direction of ion flow. E. coli and Salmonella cells can swim in a straight line by bundling left-handed helical filaments behind the cell body (run) when all of them rotate in CCW direction. When one or multiple motors switch the direction of rotation from $\mathrm{CCW}$ to $\mathrm{CW}$, the flagellar bundle is disrupted, enabling the cell to tumble and change the swimming direction. E. coli and Salmonella cells sense temporal changes in nutrients, environmental stimuli, and signaling molecules to coordinate the switching frequency of the motor. Transmembrane chemoreceptors, energy-related taxis sensors and intracellular phosphotransferase systems detect environmental signals and then convert them into intracellular signals. Then, an intracellular signal transduction system transmits the signals to the flagellar motor to switch the direction of motor rotation from CCW to CW. The cells repeat a run-tumble pattern to explore more favorable environments for their survival [15]. This review article covers our current understating of flagella-driven motility mechanism in E. coli and Salmonella. We also describe the structural and functional diversities of the bacterial flagella.

\section{Axial Structure}

The axial structure of the bacterial flagellum is commonly a helical assembly composed of 11 protofilaments and is divided into at least three structural parts: the rod, the hook and the filament from the proximal to the distal end. The rod is straight and rigid against bending and twisting and acts as a drive shaft. The hook is supercoiled and flexible against bending and acts as a universal joint to smoothly transmit torque produced by the motor to the filament. The filament is also supercoiled but stiff against bending. The filament is normally a left-handed supercoil to act as a helical screw 
to produce thrust for swimming motility. The filament undergoes polymorphic transformation from the left-handed supercoil to right-handed ones when bacterial cells tumble and change swimming direction [16].

\subsection{Flagella Filament}

The flagellar filament of E. coli is formed by $\sim 30,000$ copies of flagellin, FliC. Salmonella has the $f l j B$ gene encoding another flagellin subunit in addition to the $f l i C$ gene. Because flagellin is a major target of host immune system ( $\mathrm{H}$-antigen), such an additional flagellin subunit enables Salmonella cells to escape from adaptive immune response of the host more efficiently compared to E. coli cells [17]. The FliC-type filament structure derived from Salmonella has been solved at the atomic level [18-20]. Salmonella FliC is composed of four domains D0, D1, D2 and D3, arranged from the inner to the outer part of the filament structure. Domains D0 and D1 are well conserved among bacterial species whereas domains D2 and D3 are variable even among Salmonella spp., because these two domains are the major targets of antibodies [21].The supercoiled forms of the filament structure are generated by combinations of two distinct left-handed (L-type) and right-handed (R-type) helical conformations of flagellin molecule and packing interactions of the L- and R-type protofilaments, and so the helical properties of each supercoil are determined by a ratio of L-type protofilaments to R-type ones in the filament structure [22,23]. The intermolecular distance along the L-type straight filament consisting of all L-type protofilaments is $0.8 \AA$ longer than that of the R-type one composed of all R-type protofilaments [24]. Since a conformational change of a $\beta$-hairpin in domain D1 generates the $0.8 \AA$ difference in repeat distance, this $\beta$-hairpin is thought to be responsible for the supercoiling switching [17]. Therefore, it seems likely that an abrupt reversal of motor rotation applies mechanical stress on each protofilament to induce the sliding motion between flagellin subunits along the protofilament, thereby changing the filament structure from the L-type supercoil to R-type one to disrupt the flagellar bundle for tumbling of the cell body [18]. Recent high-resolution electron cryomicroscopy (cryoEM) imaging analyses of L- and R-type straight filaments derived from Bacillus subtilis and P. aeruginosa have shown that the switching of the supercoiled forms of these flagellar filaments occurs in a way similar to the Salmonella filament [25].

Although the flagellar filaments of E. coli and Salmonella are formed by a single flagellin subunit, many bacterial species have multiple flagellins for the synthesis of flagellar filaments. The single polar flagellum of Caulobacter crescentus is composed of six flagellins, FljJ, FljK, FljL, FljM, FljN, and FljO [26]. Although the function of each flagellin subunit and their organization are not yet characterized, they are not essential for filament formation because some flagellin defects are compensated by others [26]. The flagellar filament of Sinorhizobium meliloti consists of four flagellins, FlaA, FlaB, FlaC, and FlaD, and that of Rhizobium lupini contains just three of them FlaA, FlaB, and FlaD. For the flagella of these soil bacteria, FlaA is the principal component, and others are secondary ones [27]. The flagellar filament of Rhizobium leguminosarum comprises three major proteins, FlaA, FlaB, and FlaC, and four minor proteins, FlaD, FaE, FlaH, and FlaG [28]. Agrobacterium tumefaciens also possesses four flagellins, FlaA, FlaB, FlaC, and FlaD; FlaA and FlaB are abundant in the filament in comparison with FlaC and $\mathrm{FlaD}$, and the swimming ability of $A$. tumefaciens is considerably decreased by a loss of FlaA but not by that of FlaB [29]. Bradyrhizobium diazoefficiens has two flagella systems: One is subpolar flagella, of which filament is composed of four flagellins, FliC1, FliC2, FliC3, and FliC4, whereas the other is lateral flagella, of which filament is made up of two flagellins, LafA1 and LafA2 [30]. The bi-polar flagellar filaments of Campylobacter jejuni comprise two distinct FlaA and FlaB subunits, both of which share $92.3 \%$ sequence identity. The FlaB filament grows first and then FlaA filament grows on the FlaB filament [31]. Consistently, two different flagellins, FlaA and FlaB ( $86 \%$ sequence identity) form the single polar flagellar filament in Shewanella putrefaciens, and FlaA forms a proximal part of the filament whereas FlaB makes the remaining portion [32]. The spatial assembly by these two distinct flagellin subunits benefits motility under a various range of environmental conditions [32]. Because the assembly of the flagellar filament by multiple flagellins affects its mechanistic properties for flagellar 
function in different environments [26,32-35], the composition of the flagellar filament structure would be optimized for environmental conditions, in which the bacteria live and survive.

\subsection{Hook and Rod}

The Salmonella hook is formed by about 120 copies of the hook protein FlgE. Salmonella FlgE consists of three domains D0, D1, and D2, arranged from the inner to outer parts of the hook structure and the Dc region connecting domains D0 and D1 [36,37]. The hook forms several supercoils, and axial interactions between a triangular loop of domain D1 and domain D2 are responsible for hook supercoiling [36,38,39]. However, a truncation of neither the triangular loop nor the D2 domain affects the bending flexibility of the hook structure [38]. Since there are gaps not only between D1 domains but also between D0 domains, these gaps make the hook flexible for bending. The amino-acid sequence of FlgE of $C$. jejuni (864 a.a for strain NCTC 11168) is much longer than that of Salmonella (402 a.a), and so FlgE of C. jejuni has two additional outer domains, D3 and D4, and these two domains are involved in the interaction within and between protofilaments, conferring stiffness and robustness on the $C$. jejuni hook structure to act as a universal joint under highly viscous condition [40].

The bending flexibility of the hook structure is required for the formation of a bundle structure behind the cell body of E. coli and Salmonella [41,42]. The hook length is also important for maximum stability of the flagellar bundle. Shorter hooks are too stiff to function as a universal joint whereas longer hooks buckle and create instability in the flagellar bundle [43]. The hook length is controlled by the molecular ruler protein FliK, which is secreted via a type III protein export apparatus during hook assembly [44].

The elasticity of the hook is also important for changing swimming direction in $V$. alginolyticus, which is a monotrichous bacterium. When $V$. alginolyticus cell changes swimming from forward to backward by the switching of direction of flagellar motor rotation from $\mathrm{CCW}$ to $\mathrm{CW}$, the hook undergoes compression and buckles, resulting in an axis mismatch between the flagellar filament and the cell body to induce a flicking motion of the cell body. As a result, the swimming direction changes by $\sim 90^{\circ}[45]$.

The rod is composed of three proximal rod proteins, $\mathrm{FlgB}, \mathrm{FlgC}, \mathrm{FlgF}$, and the distal rod protein FlgG [46,47]. FliE is postulated to connect the MS ring and the most proximal part of the rod formed by FlgB [48]. These four rod proteins and FliE are well conserved among bacterial species $[9,10]$. Domains D0 and D1 of Salmonella FlgG show high sequence and structural similarities to those of FlgE, thereby allowing direct connection of the rigid rod with the flexible hook [49]. However, one major structural difference between the rod and hook is the orientation of their D1 domains relative to the tubular axis, and so axial packing interactions between domains D1 of FlgG are tight whereas those of FlgE are loose. As a result, such a structural difference is likely to be responsible for the bending rigidity of the rod and flexibility of the hook [49]. The Dc region of FlgG has a FlgG specific sequence (GSS; YQTIRQPGAQSSEQTTLP). Since the GSS insertion into the Dc region of FlgE makes the hook straight and rigid, the GSS contributes to the rigidity on the rod structure [42]. However, since FlgE of B. subtilis and C. jejuni has the GSS-like sequence in their Dc region [32,34], it remains unknown how the hook of B. subtilis and C. jejuni can form a curved structure with bending flexibility.

\section{Type III Protein Export Apparatus}

The assembly of the axial structure begins with the rod, followed by the hook and finally the filament. A type III protein export apparatus transports axial component proteins from the cytoplasm to the distal end of the growing flagellar structure to construct the axial structure beyond the cellular membranes [50]. The type III protein export apparatus consists of an export gate complex made of five transmembrane proteins, FlhA, FlhB, FliP, FliQ and FliR, and a cytoplasmic ATPase ring complex consisting of FliH, FliI and FliJ [51-53]. The transmembrane export gate complex is located within the basal body MS ring and acts as a $\mathrm{H}^{+}$-protein antiporter to couple an inward-directed $\mathrm{H}^{+}$translocation through the export gate with an outward-directed protein export [54,55]. FliP, FliQ, and FliR form 
a right-handed helical assembly with a $5 \mathrm{FliP}$ to 4 FliQ to 1 FliR stoichiometry inside the MS ring, and FliO is required for efficient assembly of the FliPQR complex [52,56,57]. The FliPQR complex has a central channel with a diameter of $1.5 \mathrm{~nm}$ [57]. Since FliP and FliR are likely to interact with FliE $[51,57,58]$, the central channel of the FliPQR complex is postulated to be a protein translocation pathway. FlhA and FlhB associate with the FliPQR complex [52]. FlhA forms a nonameric ring structure through its C-terminal cytoplasmic domain [59-61] and forms an ion channel to conduct both $\mathrm{H}^{+}$ and $\mathrm{Na}^{+}$[62]. FliH, FliI and FliJ form the cytoplasmic ATPase ring complex with a $12 \mathrm{FliH}$ to 6 FliI to 1 Flij stoichiometry [63-65]. The ATPase ring complex is associated with the basal body through interactions of FliH with FlhA and a $\mathrm{C}$ ring protein FliN [66-69]. The FliI $\mathrm{I}_{6}$ ring hydrolyzes ATP to activate the transmembrane export gate complex, thereby driving $\mathrm{H}^{+}$-coupled flagellar protein export by the export gate $[55,70]$.

\section{Basal Body Rings}

The basal body has multiple ring structures, namely L ring, P ring, MS ring, and C ring [71] (Figure 1c). The $\mathrm{L}$ and $\mathrm{P}$ rings, which are formed by the lipoprotein $\mathrm{FlgH}$ and the periplasmic protein FlgI, respectively, are embedded in the outer membrane and the peptidoglycan (PG) layer, respectively, and they together act as a bearing for the rod. The LP ring complex is missing in the basal body of gram-positive bacteria such as B. subtilis [9]. In contrast, the MS and C rings are well conserved among bacterial species $[9,10]$. The MS ring is composed of the transmembrane protein FliF and is part of a rotor [71]. FliG, FliM, and FliN form the $\mathrm{C}$ ring on the cytoplasmic face of the $\mathrm{MS}$ ring. The $\mathrm{C}$ ring acts not only as a central part of the rotor for torque generation but also as a structural device to switch the direction of motor rotation in E. coli and Salmonella [71]. Diameters of the LP ring complex, the S ring, the $\mathrm{M}$ ring, and the $\mathrm{C}$ ring are $\sim 25 \mathrm{~nm}, \sim 24.5 \mathrm{~nm}, \sim 30 \mathrm{~nm}$, and $\sim 45 \mathrm{~nm}$, respectively, in Salmonella.

FliG consists of $\mathrm{N}$-terminal $\left(\mathrm{FliG}_{\mathrm{N}}\right)$, middle $\left(\mathrm{FliG}_{\mathrm{M}}\right)$, and C-terminal $\left(\mathrm{FliG}_{\mathrm{C}}\right)$ domains. $\mathrm{FliG}_{\mathrm{N}}$

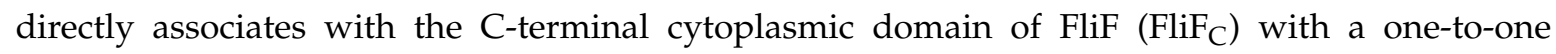
stoichiometry [72]. Inter-molecular interactions between $\mathrm{FliG}_{\mathrm{N}}$ domains and between $\mathrm{FliG}_{\mathrm{M}}$ and FliG $_{C}$ are responsible for FliG polymerization on the cytoplasmic face of the MS ring [73-76]. FliG ${ }_{C}$ is involved in the interaction with the stator protein MotA [77-79]. The middle domain of FliM (FliM $\left.{ }_{M}\right)$ binds to FliG $_{M}$ with a one-to-one stoichiometry to form the $C$ ring wall [80]. An EHPQR motif in FliG and a GGXG motif in $\mathrm{FliM}_{\mathrm{M}}$ are responsible for the $\mathrm{FliG}_{\mathrm{M}}-\mathrm{FliM}_{\mathrm{M}}$ interaction. The C-terminal domain of FliM $\left(\right.$ FliM $\left._{C}\right)$ shows significant sequence and structural similarities with FliN, and FliM ${ }_{C}$ and FliN together form a doughnut-shaped hetero-tetramer consisting of one copies of $\mathrm{FliM}_{\mathrm{C}}$ and three copies of FliN, and this hetero-tetrameric block produces a continuous spiral density along the circumference at the bottom edge of the $C$ ring [81]. B. subtilis has a fliY gene, which shows sequence similarity to both FliM $_{C}$ and FliN, instead of the fliN gene [82]. In B. subtilis, FliG, FliM and FliY form the C ring in a similar manner to E. coli and Salmonella C ring structures although the overall structure and dimensions of the B. subtilis $\mathrm{C}$ ring remain unclear. Interestingly, high-resolution single-molecule fluorescence imaging techniques have revealed rapid exchanges of FliM and FliN labelled with a fluorescent protein between the basal body and the cytoplasmic pool in E. coli, suggesting that the $\mathrm{C}$ ring is a highly dynamic structure [83-85].

The stator units are assembled on the FliG ring (Figure 1c), and so stator-rotor interactions occur about $20 \mathrm{~nm}$ away from the center of the C ring in Salmonella. The Salmonella flagellar motor can accommodate about 10 stator units [86]. A fliF-fliG deletion fusion significantly shortens the diameter of the $\mathrm{C}$ ring, because $\mathrm{FliF}_{\mathrm{C}}$ and $\mathrm{FliG}_{\mathrm{N}}$, which together form the inner lobe structure connecting the $\mathrm{M}$ and $\mathrm{C}$ rings, are missing. It has been shown that the average number of active stator units is two units less in the FliF-FliG deletion fusion motor than in the wild-type motor [87]. This suggests that the diameter of the $C$ ring determines the number of active stator units that can be bound to the motor. This is supported by recent observations that a diameter of the $\mathrm{C}$ ring of the C. jejuni and H. pylori flagellar motors is larger than that of the Salmonella $\mathrm{C}$ ring, allowing these motors to accommodate more active stator units around the rotor to generate much higher torque [88]. 


\section{Stator}

\subsection{Diversity of the Stator Unit}

The transmembrane stator unit of the flagellar motor conducts ions and exerts force on the rotor. Based on the coupling ion and sequence similarity, the stator units are classified into three groups: $\mathrm{H}^{+}$-coupled MotAB complex, $\mathrm{Na}^{+}$-coupled PomAB complex, and $\mathrm{Na}^{+}$-coupled MotPS complex [14]. The MotAB complex is composed of four copies of MotA and two copies of MotB and acts as a transmembrane $\mathrm{H}^{+}$channel $[89,90]$. The PomAB and MotPS complexes form a $\mathrm{Na}^{+}$channel in a way similar to the MotAB complex [91-93]. In addition to these stator proteins, bacteria such as S. meliloti and $V$. alginolyticus have additional motor proteins. S. meliloti possesses three extra motor proteins, namely MotC, MotD, and MotE. MotC stabilizes the periplasmic domain of MotB to facilitate proton translocation through a $\mathrm{H}^{+}$channel of the MotAB complex. MotD binds to FliM for fast rotation, and MotE is involved in folding and stability of MotC [94]. V. alginolyticus has MotX and MotY to form the $\mathrm{T}$ ring structure located beneath the $\mathrm{P}$ ring, and an interaction between PomB and MotX is required for stable localization of PomAB complex around the basal body [9,95].

$V$. alginolyticus and $V$. parahaemolyticus use a single polar flagellum for swimming in low viscous liquid and induce lateral flagella when these Vibrio cells encounter solid surfaces [96-98]. The polar flagellum utilizes the Pom $A B$ complex as a stator unit whereas the lateral flagella use the Mot $A B$ complex as a stator unit [99]. B. subtilis possesses two distinct $\mathrm{H}^{+}$-type $\mathrm{Mot} \mathrm{AB}$ and $\mathrm{Na}^{+}$-type MotPS complexes to drive flagellar motor rotation, and these two types of stator units are exchanged in response to changes in external $\mathrm{pH}$, external $\mathrm{Na}^{+}$concentration and viscosity $[92,93,100]$. Like B. subtilis, Shewanella oneidensis also utilizes two distinct $\mathrm{H}^{+}$-type MotAB and $\mathrm{Na}^{+}$-type PomAB complexes in response to changes in the environmental $\mathrm{Na}^{+}$concentration [101].

The MotPS complex of Bacillus alcalophilus conducts $\mathrm{K}^{+}$and $\mathrm{Rb}^{+}$in addition to $\mathrm{Na}^{+}$[102]. Bacillus clausii has only Mot $\mathrm{AB}$ complex as a stator unit, and this Mot $\mathrm{AB}$ complex exhibits the $\mathrm{H}^{+}$channel activity at neutral $\mathrm{pH}$ and the $\mathrm{Na}^{+}$channel activity at extremely high $\mathrm{pH}$ [103]. The MotAB complex of a spirochete Leptospira biflexa has the ability to conduct both $\mathrm{H}^{+}$and $\mathrm{Na}^{+}$in an external $\mathrm{pH}$-dependent manner in a way similar to the MotAB complex of B. clausii [104]. These observations suggest that the stator function of these species would be optimized for environmental conditions of their habitats.

\subsection{Topology of the Stator Complex}

MotA, PomA and MotP possess four transmembrane helices (TM1, TM2, TM3, and TM4) and a relatively large cytoplasmic loop between TM2 and TM3 and a C-terminal cytoplasmic tail (Figure 2a). MotB, PomB and MotS possess an N-terminal cytoplasmic tail, a single transmembrane helix, and a relatively large C-terminal periplasmic domain containing a conserved peptidoglycan-binding (PGB) motif for anchoring the stator units to the rigid PG layer (Figure 2a). A plausible atomic model of the transmembrane $\mathrm{H}^{+}$channel of the MotAB stator complex derived from E. coli has been proposed [105]. The MotAB stator complex has two $\mathrm{H}^{+}$pathways formed by MotA-TM3, MotA-TM4 and MotB-TM (Figure 2b). A highly conserved Asp-32 residue lies near the cytoplasmic end of MotB-TM and plays an important role in the $\mathrm{H}^{+}$relay mechanism [106]. This Asp residue is located on the surface of MotB-TM facing MotA-TM3 and MotA-TM4 [90]. A plug segment in the flexible linker of MotB connecting MotB-TM and the PGB domain binds to the $\mathrm{H}^{+}$channel to suppress massive $\mathrm{H}^{+}$flow through the channel until the Mot $\mathrm{AB}$ complex associates with the motor. It has been proposed that an interaction between MotA and FliG may induce a detachment of the plug segment form the $\mathrm{H}^{+}$ channel to couple the $\mathrm{H}^{+}$flow through the channel to torque generation $[107,108]$. 


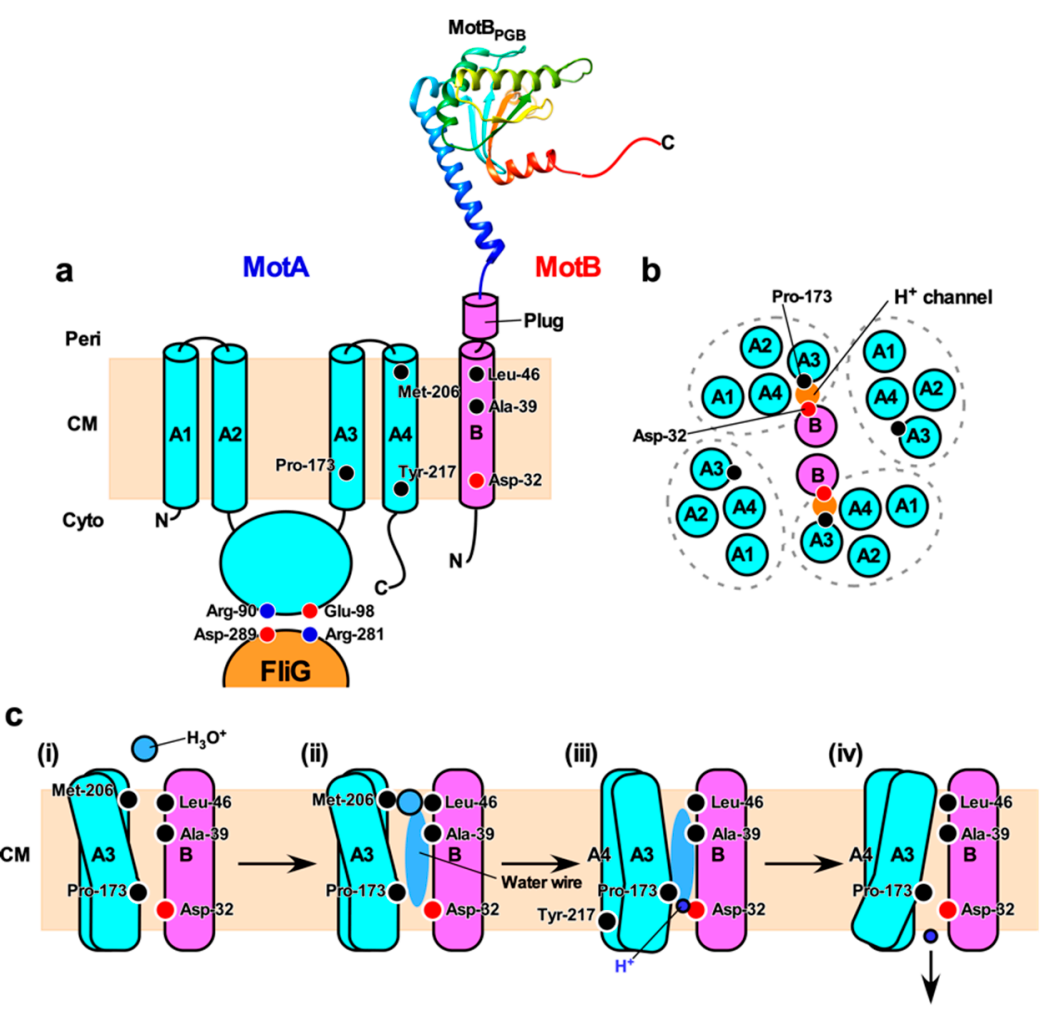

Figure 2. $\mathrm{H}^{+}$translocation mechanism of the flagellar motor. (a) Topology of the E. coli MotA and MotB and a crystal structure of the peptidoglycan-binding domain of MotB (MotB PGB $_{\text {, PDB code: }}$ 2ZVY). Highly conserved Arg-90 and Glu-98 residues in the cytoplasmic loop between transmembrane helices 2 (A2) and 3 (A3) interact with conserved Asp-289 and Arg-281 residues of FliG, respectively, to drive motor rotation. Asp-32 of MotB provides a binding site for $\mathrm{H}^{+}$. Pro-173, Met-206 and Tyr-217 of MotA and Ala-39 and Leu-46 of MotB are involved in the $\mathrm{H}^{+}$relay mechanism. Cyto, cytoplasm; $\mathrm{CM}$, cytoplasmic membrane; Peri, periplasm. (b) Arrangement of transmembrane segments of MotA and MotB. The MotAB complex has two proton channels. Four MotA subunits are positioned with their TM3 (A3) and TM4 (A4) segments adjacent to the MotB dimer, and their TM1 (A1) and TM2 (A2) segments on the outside. (c) A plausible model for $\mathrm{H}^{+}$translocation through MotAB stator complex (see text for details).

\section{3. $\mathrm{H}^{+}$Translocation Mechanism}

The maximum rotation rate of the $\mathrm{H}^{+}$-driven flagellar motors of E. coli and Salmonella is reduced with a decrease in the intracellular $\mathrm{pH}$. In contrast, a change in external $\mathrm{pH}$ does not affect the maximum motor speed at all. These observations suggest that the intracellular $\mathrm{H}^{+}$concentration affects the rate of the $\mathrm{H}^{+}$flow through the MotAB complex $[109,110]$.

Asp-33 of Salmonella MotB, which corresponds to Asp-32 in E. coli MotB, is critical for the binding of $\mathrm{H}^{+}$from the cell exterior, and its protonation and deprotonation cycle is directly linked to a torque generation step caused by stator-rotor interactions [111]. The motB(D33E) mutation results in a considerable decrease in the rate of $\mathrm{H}^{+}$-coupled conformational change of the MotAB complex [112]. Furthermore, the $\operatorname{mot} B(D 33 E)$ mutation causes not only large speed fluctuations but also frequent pausing of motor rotation at low load. However, neither speed fluctuation nor pausing is seen at high load [112]. These observations suggest that the protonation and deprotonation cycle of Asp-33 of MotB may occur in a load-dependent manner. The dissociation of $\mathrm{H}^{+}$from this Asp-33 residue to the cytoplasm is linked to conformational changes of a cytoplasmic loop of MotA, which is responsible for the interaction with FliG. Molecular dynamics (MD) simulation has predicted that the binding of $\mathrm{H}^{+}$to this Asp residue induces a conformational change of the proton channel to facilitate $\mathrm{H}^{+}$release to the 
cytoplasm [105]. Two highly conserved residues, Pro-173 of MotA-TM3 and Tyr-217 of MotA-TM4, are involved in such $\mathrm{H}^{+}$-coupled conformation changes of the $\mathrm{H}^{+}$channel [113-115].

Based on MD simulation of the $\mathrm{H}^{+}$channel of the E. coli MotAB complex, the $\mathrm{H}^{+}$translocation through the channel is postulated to be mediated by water molecules aligned along a $\mathrm{H}^{+}$pathway (i.e., water wire). Leu- 46 of MotB is assumed to act as a gate for hydronium ion $\left(\mathrm{H}_{3} \mathrm{O}^{+}\right)$and then to transfers $\mathrm{H}^{+}$to MotB-Asp32 via the water wire [105]. Mutations at position of Ala-39 of MotB, which resides on the same side as Asp-32 in the $\mathrm{H}^{+}$pathway, impair motility and are partially suppressed by extragenic mutations at Met-206 of MotA [116]. This Met-206 residue is located near the periplasmic end of TM4 and faces the $\mathrm{H}^{+}$pathway [105,117]. The motA(M206I) mutation reduces the $\mathrm{H}^{+}$channel activity, thereby reducing motility [118]. Taken all together, the $\mathrm{H}^{+}$translocation mechanism is postulated to be as follows: (i) $\mathrm{H}^{+}$permeates a $\mathrm{H}^{+}$channel in the $\mathrm{H}_{3} \mathrm{O}^{+}$state through Leu-46 of MotB, (ii) Met-206 of MotA and Ala-39 of MotB are involved in the transfer of $\mathrm{H}^{+}$along the water wire, (iii) $\mathrm{H}^{+}$binds to $\mathrm{Asp}-32$ of MotB, and (iv) the dissociation of $\mathrm{H}^{+}$from Asp-32 of MotB to the cytoplasm is facilitated by a conformational change of the $\mathrm{H}^{+}$channel through Pro- 173 and Tyr-217 of MotA (Figure 2c). As a result, the cytoplasmic loop of MotA can interact with FliG to drive flagellar motor rotation [119].

\section{Torque Generation}

\subsection{Rotation Mechanism}

Highly conserved Arg-90 and Glu-98 residues of MotA, which are located in the cytoplasmic loop between TM2 and TM3 of MotA, interact with highly conserved Asp-289 and Arg-281 residues of FliG, respectively (Figure 2a) [77-79,120]. These two electrostatic interactions are responsible for efficient stator assembly around the rotor, and the interaction between Glu-98 of MotA and Arg-281 of FliG is likely to be involved in torque generation [79]. $\mathrm{H}^{+}$translocation through the transmembrane $\mathrm{H}^{+}$ channel of the MotAB complex allows the cytoplasmic loop of MotA to associate with and dissociate from FliG to drive flagellar motor rotation [119]. However, the energy coupling mechanism of the flagellar motor remains unknown.

\subsection{Torque-Speed Relationship}

Precise measurements of motor rotation are important to elucidate the torque-generation mechanism of the flagellar motor. Direct evidence that the bacterial flagellum is a rotary motor is obtained by tethered cell assay (Figure 3a), in which the cell body rotates by tethering the filament to a glass surface [121]. The tethered cell assay is a simple method to measure the rotation of the flagellar motor to give fundamental knowledges on the motor mechanism. However, the maximum speed of tethered cells is limited below $20 \mathrm{~Hz}$, because a cell body ( 2 $\mu \mathrm{m}$ in length) is extremely large load against the flagellar motor ( $\sim 5 \mathrm{~nm}$ in diameter). To measure the rotational speeds of the E. coli flagellar motor over a wide range of external load, bead assay was developed by the Howard Berg laboratory (Figure 3b) [11,122,123]. A bead is attached to a partially sheared sticky flagellar filament lacking domain D3 of flagellin as a probe, and then the rotation of the bead is recoded by a quadrant photodiode or a high-speed camera with high temporal and special resolutions. Therefore, bead assays enable us to investigate output properties of the flagellar motor over the wide range of external load by changing the bead size and medium viscosity. Viscous drags on a bead $\left(\gamma_{\mathrm{b}}\right)$ and a truncated filament $\left(\gamma_{\mathrm{f}}\right)$ are obtained from the bead diameter and the flagellar morphology (filament length and thickness, and helical pitch and radius), respectively, based on a hydrodynamic theory [124,125], and so motor torque $(M)$ can be estimated by $M=\left(\gamma_{\mathrm{b}}+\gamma_{\mathrm{f}}\right) \cdot 2 \pi f$, where $f$ is the rotation rate.

Figure $3 \mathrm{c}$ shows a schematic diagram of the torque versus speed relationship of the flagellar motor, namely torque-speed curve. The torque-speed curve of the flagellar motor consists of two regimes: a high-load, low-speed regime and a low-load, high-speed regime [11]. As external load is decreased, torque decreases gradually up to a certain speed and then falls rapidly to zero. The rotation rate of 
the flagellar motor is proportional to IMF over a wide range of external load (Figure 3d) [126,127]. Both deuterium oxide and temperature affect the rotation rate of the E. coli motor operating in the low-load, high-speed regime but not in the high-load, low-speed regime (Figure 3d), suggesting that a steep decline of torque seen in the low-load, high-speed regime is limited by the rate of $\mathrm{H}^{+}$-coupled conformational changes of the MotAB complex [11,123]. Torque at high load is dependent on the number of active stator units in the motor, whereas the maximum motor speed near zero load is independent of the stator number $[122,128,129]$. However, recent two biophysical analyses have revealed that the maximum speed near zero load increases with an increase in the number of active stator units in the motor $[130,131]$, suggesting that both torque and speed would be proportional to not only IMF but also to the stator number over a wide range of external load.

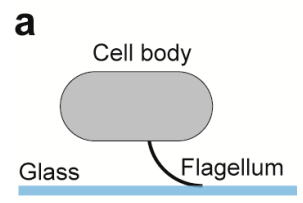

C

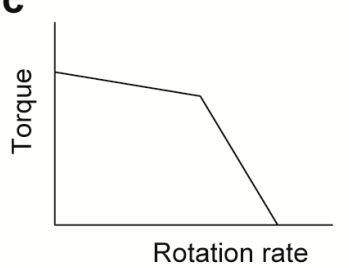

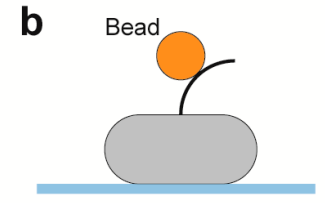

d

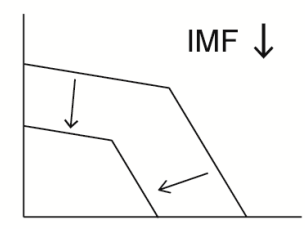

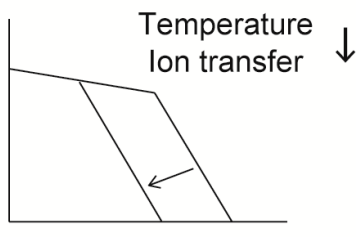

Figure 3. Characterization of the rotation of the flagellar motor. (a) Tethered cell assay. (b) Bead assay; gold nanoparticles (60-100 $\mathrm{nm}$ in diameter) and polystyrene beads (0.2-2.0 $\mu \mathrm{m}$ in diameter) are used. (c) A schematic of the torque-speed curve. (d) Effects of factors relevant to motor dynamics on the torque-speed curve. Dependence of the curve on the number of stator units is described in the section of Duty ratio.

\subsection{Stepwise Rotation}

Discretely stepwise movements have been observed in many molecular motors. For example, kinesin, which is an ATP-driven linear motor, moves along a microtubule with steps of $8 \mathrm{~nm}$ interval [132]; myosin $\mathrm{V}$ on an actin filament shows stepwise movements with $36 \mathrm{~nm}$ intervals with $90^{\circ}$ random rotation either $\mathrm{CCW}$ or $\mathrm{CW}$ [133]; and $\mathrm{F}_{1}$-ATPase, which is the ATP-driven rotary motor, shows a $120^{\circ}$ step, which is further divided into $80^{\circ}$ and $40^{\circ}$ substeps [134]. Such stepwise movements reflect the elementary process of mechanochemical energy coupling, e.g., $80^{\circ}$ and $40^{\circ}$ substeps in $\mathrm{F}_{1}$-ATPase are coupled with ATP binding and Pi release, respectively, and thus kinetics and dynamics of the step events are important for understanding the motor mechanism. When the flagellar motor labelled with a small bead (diameter: $\sim 100 \mathrm{~nm}$ ) contains only a single stator unit around a rotor and spins at a few $\mathrm{Hz}$, stepping motions of the motor has been observed. The flagellar motor containing a single stator unit rotates with 26 steps per revolution in both CCW and CW directions [135,136]. Since the number of steps per revolution is consistent with the rotational symmetry of the FliG ring, it is suggested that torque is generated through cyclic association-dissociation of MotA with every FliG subunit along the circumference of the rotor and that such an elementary process is symmetric in $\mathrm{CCW}$ and $\mathrm{CW}$ rotation. However, it remains unknown how the protonation-deprotonation cycle of Asp-32 of MotB is linked to the cyclic association-dissociation of MotA with FliG.

\subsection{Duty Ratio}

The duty ratio is defined as a fraction of time that a stator unit is bound to a rotor in the mechanochemical cycle of the flagellar motor. The duty ratio is one of the fundamental properties 
of molecular motors and is an important parameter for understanding the operation mechanism. The duty ratio of the flagellar motor has been discussed based on the dependency of the rotation rate on the number of active stator units in the motor [122,128-131]. At high load where torque generation against load is a rate limiting step, the rotation rate is proportional to the number of active stator units in the motor regardless of the value of the duty ratio: If the duty ratio is large $(\sim 1)$, the rotation rate is proportional to the sum of the applied torque because multiple stator units work together at the same time; If the duty ratio is small $(<<1)$, each stator unit works independently and so the probability of torque generation by the motor per a certain period of time is increased with an increase in the number of active stator units in the motor. As a result, the rotational speed of the flagellar motor is proportional to the number of active stator units in the motor. At low load where kinetic processes (e.g., proton translocation and conformational change) are rate limiting steps, the relationship between the rotation rate and the number of active stator units would depend on the duty ratio: If the duty ratio is close to 1 , total torque does not affect the rotation rate, and so the rotation rate of the motor does not depend on the number of active stator units in the motor; if the duty ratio is small, the probability of torque generation by stator-rotor interactions is increased with an increment in the stator number. Ryu et al. have shown that the stator number dependence of the rotational speed of the E. coli flagellar motor becomes smaller when external load becomes lower [122]. Furthermore, Yuan and Berg have shown that the maximum speed of the E. coli motor is independent of the number of active stator units in the motor [128]. Recently, Wang et al. have reported that the maximum speed of the E. coli motor near zero load is constant although the number of active stator units varies [129]. These three studies have suggested that the duty ratio of the flagellar motor seems to be large. Assuming that the flagellar motor has a high duty ratio, theoretical studies can reproduce the output properties of the flagellar motor such as a torque-speed curve [137-141]. In contrast, a recent study using a hybrid motor containing both $\mathrm{H}^{+}$-type and $\mathrm{Na}^{+}$-type stator units in $E$. coli cells has shown that the maximum speed of the hybrid flagellar motor near zero load varies with the number of active stator units in the motor [130]. This observation is supported by recent observation that the zero-torque speed of the Salmonella flagellar motor depends on the number of active stator units in the motor [131]. These suggest that the duty ratio of the flagellar motor operating at low load is smaller than the previous thought. By removing the high duty ratio constraint from the theoretical model, it is also possible to reproduce the stator-number-dependent rotational speed close to zero load. This physical model also predicts that the duty ratio will become larger with increase in the number of active stator units when the motor operates at low load and that a high duty ratio will be required for the motor to processivity generate much larger torque at high load [142]. Thus, the duty ratio of the flagellar motor is currently controversial, and hence further experimental verification over a wide range of external load will be necessary.

\section{Switching of Direction of Flagellar Motor Rotation}

\subsection{Conformational Changes for Reversal of Motor Rotation}

E. coli and Salmonella cells sense temporal changes in chemical concentrations of attractants and repellents via transmembrane chemoreceptors (methyl-accepting chemotaxis proteins, MCP) localized near the cell pole [143]. The binding of repellent to MCP induces auto-phosphorylation of CheA via the adopter protein $\mathrm{CheW}$, and then CheA-P transfers a phosphate to the response regulator CheY. The binding of the phosphorylated form of CheY (CheY-P) to FliM and FliN induces the structural remodeling of the $\mathrm{C}$ ring responsible for the switching of direction of flagellar motor rotation from CCW to CW. The relationship between the switching frequency and CheY-P concentration shows a sigmoid curve with a Hill coefficient of $\sim 10$ [144]. This switching Hill coefficient value is larger than the Hill coefficient estimated from the binding affinity of CheY-P for the motor [145,146]. This suggests that CheY-P-dependent structural remodeling of the $\mathrm{C}$ ring occurs in a highly cooperative manner. 
Since the elementary process of torque generation by stator-rotor interactions is symmetric in CCW and $\mathrm{CW}$ rotation, $\mathrm{FliG}_{\mathrm{C}}$, which contains highly conserved Arg-281 and Asp-289 residues involved in the interaction with MotA, is postulated to rotate $180^{\circ}$ relative to MotA [136]. FliG $\mathrm{C}_{\mathrm{C}}$ has a highly flexible MFXF motif between FliG $\mathrm{CN}_{\mathrm{CN}}$ and FliG $\mathrm{CC}_{\mathrm{C}}$ subdomains and so the MFXF motif allows FliG $\mathrm{CC}_{\mathrm{C}}$ to rotate $180^{\circ}$ relative to $\mathrm{FliG}_{\mathrm{CN}}$ to reorient Arg-281 and Asp-289 residues in FliG $\mathrm{CC}_{\mathrm{C}}$ to achieve the symmetric elementary process of torque generation in both CCW and CW rotations (Figure 4) [147,148].

Helix ${ }_{\mathrm{MC}}$ is a helical linker connecting $\mathrm{FliG}_{\mathrm{M}}$ and $\mathrm{FliG}_{\mathrm{N}}$ and plays an important role in directional switching of the flagellar motor [149]. A deletion of three residues in the N-terminal end of Helix (Pro-Ala-Ala, PAA) locks the flagellar motor in the CW state even in the absence of CheY-P [149]. The PAA deletion causes conformational rearrangements of the $\mathrm{FliG}_{\mathrm{M}}-\mathrm{FliM}_{\mathrm{M}}$ interface to induce a detachment of Helix $x_{M C}$ from the interface. Furthermore, this PAA deletion induces a $90^{\circ}$ rotation of FliG $_{\mathrm{CC}}$ relative to $\mathrm{FliG}_{\mathrm{CN}}$ through the MFXF motif in solution $[75,76,149]$. This is supported by in vivo site-directed crosslinking experiments [150]. Recent cryoEM image analyses have shown that inter-subunit spacing between $\mathrm{C}$ ring proteins are closer in the $\mathrm{C}$ ring of the $\mathrm{CW}$ motor than in that of the CCW motor [87], suggesting that the binding of CheY-P to FliM and FliN significantly affects inter-molecular interactions between the $\mathrm{C}$ ring proteins. Therefore, it is possible that the binding of CheY-P to FliM and FliN changes inter-molecular FliM $_{M}-$ FliM $_{M}$, FliM $_{C}-F_{i N}$ and FliG $_{M}-F_{i i M}$ interactions in the $C$ ring to induces the dissociation of Helix $_{M C}$ from the $\mathrm{FliG}_{\mathrm{M}}-\mathrm{FliM}_{\mathrm{M}}$ interface, thereby affecting inter-molecular $\mathrm{FliG}_{\mathrm{M}}-\mathrm{FliG}_{\mathrm{CN}}$ interactions to allow $\mathrm{FliG}_{\mathrm{CC}}$ to rotate $180^{\circ}$ relative to FliG $_{\mathrm{CN}}$ through a conformational change of the MFXF motif (Figure 4).

In E. coli and Salmonella, the binding of repellent to MCP elevates the cytoplasmic CheY-P level, thereby increasing the probability that the motor spins in $\mathrm{CW}$ direction. In contrast, the chemotaxis signaling pathway and response are known to diverse among bacterial species. In B. subtilis, CheY-P acts in the opposite way to induce CCW rotation. The binding of attractant to MCP of B. subtilis facilitates phosphorylation of $\mathrm{CheY}$, and CheY-P binds to FliM to switch motor rotation from CW to CCW [151]. Rhodobacter sphaeroides possesses six CheY proteins, $\mathrm{CheY}_{1}$ to $\mathrm{CheY}_{6}$. The decreased attractant concentration increases the cytoplasmic $\mathrm{CheY}_{3}-\mathrm{P}, \mathrm{CheY}_{4}-\mathrm{P}$, and $\mathrm{CheY}_{6}-\mathrm{P}$ levels, and the binding of $\mathrm{CheY}_{6}-\mathrm{P}$ to FliM stops motor rotation with the support of $\mathrm{CheY}_{3}-\mathrm{P}$ and $\mathrm{CheY}_{4}-\mathrm{P}$ [152].

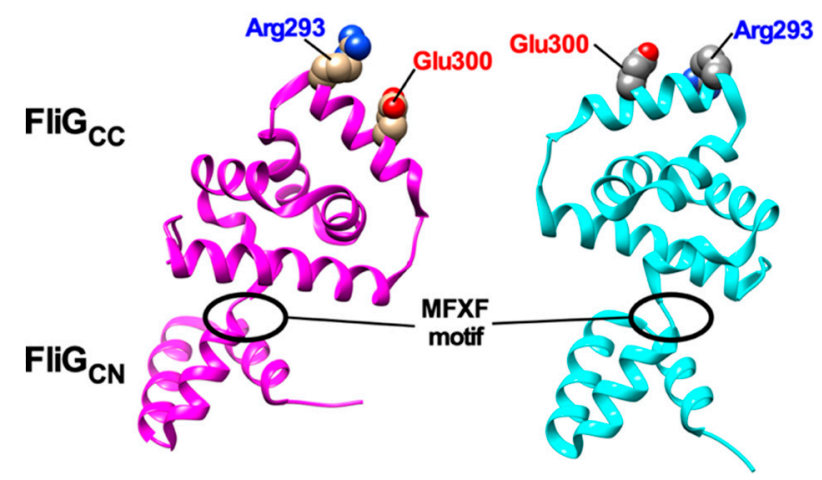

Figure 4. Structural comparisons between 3USY (cyan) and 3USW (magenta) structures of Helicobacter pylori FliG. Conformational rearrangements of the conserved MFXF motif induces a $180^{\circ}$ rotation of FliG ${ }_{C C}$ relative to FliG $_{\mathrm{CN}}$ to reorient Arg-293 and Glu-300 residues, which correspond to Arg-281 and Asp-289 of E. coli FliG, respectively.

\subsection{Conformational Spread for Cooperative Switching}

Cooperative flagellar switching can be reproduced by an Ising-type model assuming allosteric cooperativity of the conformational change in $C$ ring subunits [153]. The model assumes four states for each subunit, determined by whether a subunit conformation is placed in either the CCW or $\mathrm{CW}$ state with or without CheY-P bound. Assuming that homogeneous states of adjacent subunits (e.g., CCW-CCW-CCW or CW-CW-CW) are more stable than heterogeneous ones (e.g., CCW-CW-CCW 
or CW-CCW-CW), the directional switching is mediated by conformational changes in $\mathrm{C}$ ring subunits that extend from subunit to subunit via inter-molecular interactions between nearest adjacent subunits (Figure 5) [153]. The model prediction was verified by simultaneous measurements of motor rotation and a turnover of CheY labelled with a green fluorescent protein (GFP) between the motor and the cytoplasmic pool, showing that, in spite of the switch complex contains $~ 34$ FliM subunits, the binding of about 13 CheY-P molecules can reverse the motor [154].

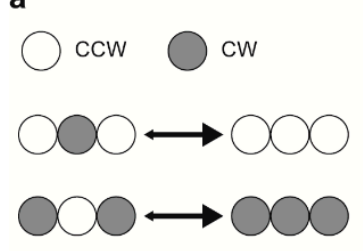

b

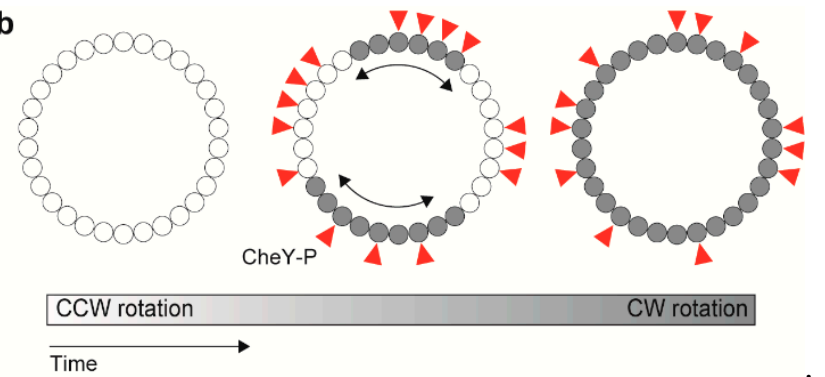

Figure 5. Model for cooperative switching between counterclockwise (CCW) and clockwise $(\mathrm{CW})$ rotations. (a) Interaction between adjacent rotor subunits. (b) Conformational spread upon CheY-P binding.

The switching rate increases until the motor speed reaches $\sim 150 \mathrm{~Hz}$, and then decreases with further increase in the rotation rate $[155,156]$. The conformational spread model also explains a speed (load) dependent switching frequency by assuming the effect of mechanical force on the switching rate, which each stator unit applies force on the FliG subunit in the C ring [140]. The conventional Ising-type conformational spread model, which is an equilibrium model sufficient for detailed balance, shows exponentially decayed distributions of the duration time for CCW or CW rotation. Such exponential duration-time distributions have been observed experimentally, suggesting the equilibrium switching system. Recently, Wang et al. have measured the CCW and CW durations at various conditions of load, PMF, and the number of active stators and have shown non-exponential shaped distributions in a torque-dependent manner. The results suggest that the flagellar switch could be a non-equilibrium system rather than an equilibrium system under certain conditions, and that motor torque is a key factor for breaking detailed balance. Furthermore, the directional switching of the flagellar motors working under non-equilibrium conditions (e.g., at high load) can occur at lower CheY-P level compared to those placed under equilibrium conditions, suggesting that the binding affinity of the flagellar motor for CheY-P is enhanced by applied force [157]. Thus, the switching of direction of flagellar motor rotation is controlled not only by the chemotactic signaling pathway but also by the mechanical force $[140,157]$.

\section{Stator Assembly}

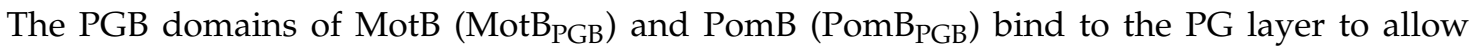
the MotAB and PomAB complexes to become an active stator unit around a rotor $[93,158,159]$. The N-terminal portions of MotB $\mathrm{PGB}_{\text {and }}$ PomB $_{\mathrm{PGB}}$ adopt a compact conformation in their crystal structure, but are structurally flexible to allow them to adopt an extended conformation as well (Figure 6). Structure-based mutational analyses of MotB $_{P G B}$ and PomB ${ }_{P G B}$ have suggested that a $5 \mathrm{~nm}$ extension of the PGB domain from the transmembrane ion channel is required for the binding of MotB $_{\mathrm{PGB}}$ and PomB $\mathrm{PGB}_{\text {to }}$ the PG layer (Figure 6) $[158,160]$. Recently, such a $5 \mathrm{~nm}$ extension process of the PGB domain of MotS (MotS $S_{\mathrm{PGB}}$ ) of $B$. subtilis has been directly visualized by high-speed atomic force

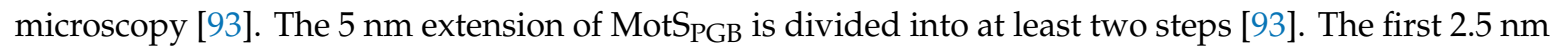
extension step is caused by a detachment of a flexible linker connecting MotS $S_{P G B}$ with MotS-TM from the transmembrane $\mathrm{Na}^{+}$channel of the MotPS complex, and the second $2.5 \mathrm{~nm}$ extension step results from an order-to-disorder transition of the N-terminal portion of MotS $S_{\mathrm{PGB}}$. Consistently, the $\operatorname{motB}(\operatorname{L119P})$ mutation in $\mathrm{MotB}_{\mathrm{PGB}}$ induces an extended conformation of the N-terminal portion of MotB $\mathrm{PGB}_{\text {[159]. }}$ 
Interestingly, the motB(L119P) mutation increases not only the PGB binding activity of MotB ${ }_{\text {PGB }}$ [159] but also the proton channel activity of the MotAB complex [107]. Therefore, it seems likely that proper positioning of an inactive MotAB complex around the rotor via stator-rotor interactions triggers a detachment of the flexible linker from the $\mathrm{H}^{+}$channel, followed by a structural transition of the N-terminal portion of MotB ${ }_{\mathrm{PGB}}$ from the compact to extended forms to become an active stator unit in the motor [159] (Figure 6).

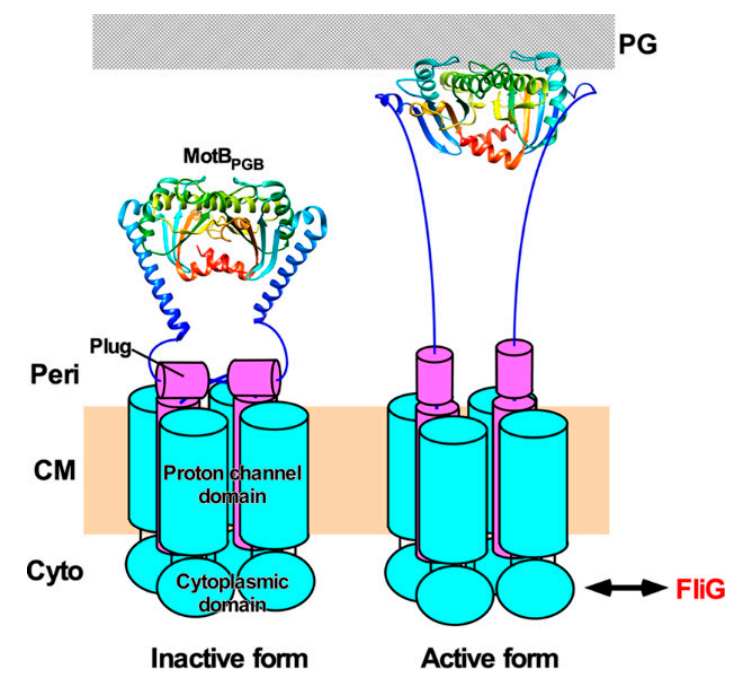

Figure 6. Activation mechanism of the $\mathrm{H}^{+}$-type MotAB complex. The MotAB complex consists of at least three structural parts: a cytoplasmic domain, a transmembrane ion channel and a peptidoglycan-binding domain [MotB PGB $_{1}$ PDB codes: 2ZVY (left panel) and 5Y40 (right panel). When the MotAB complex adopts a compact conformation, a plug segment of MotB binds to a transmembrane $\mathrm{H}^{+}$channel to suppress massive $\mathrm{H}^{+}$flow (left). When the MotAB complex encounters a rotor, electrostatic interactions between the cytoplasmic domain of MotA and FliG trigger the dissociation of the plug segment from the channel, followed by partial unfolding of the N-terminal portion of MotB $\mathrm{PGB}_{\text {to allow }}$ MotB $\mathrm{PGB}$ to bind to the peptidoglycan (PG) layer. As a result, the MotAB complex becomes an active $\mathrm{H}^{+}$-type stator unit to drive flagellar motor rotation (right).

The flagellar motor can accommodate about 10 stator units around a rotor in E. coli and Salmonella when the motor operates at high load [161]. High-resolution single molecule imaging techniques have revealed exchanges of the MotAB complex labelled with GFP between the basal body and the membrane pool during rotation at a rate constant of $0.04 \mathrm{~s}^{-1}$, indicating that the dual time of a given stator unit is about $0.5 \mathrm{~min}$. This suggests that the interaction of MotB $\mathrm{PGB}$ with the PG layer is highly dynamic, thereby allowing the MotAB complex to alternate in attachment to and detachment from the motor during motor rotation [162]. Interestingly, when external load becomes low enough, only a few stator units work around the rotor to drive motor rotation [163-165]. This suggests that such a dynamic assembly-disassembly process of the stator complex occurs in a load-dependent manner.

The number of active stator units can be estimated by resurrection experiments, in which time traces of the rotational speed of a single flagellar motor usually show stepwise speed increments and decrements. Each increment reflects the incorporation of a single MotAB complex around the rotor to become an active stator unit in the motor whereas each decrement unit reflects the disassembly of the MotAB stator complex from the rotor [163-165]. A deletion of a flexible linker connecting MotB-TM and MotB $_{\mathrm{PGB}}$ results in a rapid decrease in the number of active stator units in the motor compared to the wild-type motor, suggesting that this flexible linker of MotB modulates the binding affinity of $\mathrm{MotB}_{\mathrm{PGB}}$ for the PG layer in a load-dependent manner [166]. Certain mutations in the cytoplasmic loop of MotA, which interacts with FliG, significantly affect the mechano-sensitivity of the MotAB complex, thereby causing distinct load-dependent assembly and disassembly dynamics compared to 
the wild-type. This suggests that the cytoplasmic loop of MotA may sense a change in external load through the interaction with FliG to control the number of active stator units around the rotor [86].

How does the cytoplasmic loop of MotA transmit the mechanical signal to MotB $\mathrm{PGB}_{\mathrm{P}}$ associated with the PG layer to coordinate the number of active stator units in the motor in response to changes in external load? Nord et al. have reported that the dissociation rate of the MotAB stator complex becomes slower with an increase in applied force, thereby increasing the bound lifetime of each active stator unit incorporated into the motor, and that an abrupt relief from the stall makes the dissociation rate much faster, thereby decreasing the bound lifetime [130]. As a result, the average number of active stator units in the motor is maintained about 10 in the high-load, low speed regime whereas the stator number is decreased from 10 to a few when external load becomes quite low. Recently, it has been shown that a turnover process of the stator unit is divided into two distinct, slow (the rate constant of $\left.\sim 0.008 \mathrm{~s}^{-1}\right)$ and fast $\left(\sim 0.2 \mathrm{~s}^{-1}\right)$ steps [167]. Although the slow step called "hidden state" is not yet clarified, the fast step is assumed to reflect a rapid conformational change of MotB $\mathrm{PGB}_{\text {PG }}$ to become an active stator unit.

The assembly and disassembly dynamics of the stator complex are also affected by changes in the extracellular ion concentration $[93,101,118,168,169]$. The $\mathrm{Na}^{+}$-coupled PomAB and MotPS complexes can be assembled into a motor when the external $\mathrm{Na}^{+}$concentration is high enough $[93,101,168]$. How do the PomAB and MotPS complex sense external $\mathrm{Na}^{+}$? High-speed atomic force microscopy with high special and temporal resolutions has revealed that Mot $S_{\mathrm{PGB}}$ adopts a folded conformation in the presence of $150 \mathrm{mM} \mathrm{NaCl}$, but becomes denatured when the external $\mathrm{Na}^{+}$concentration is less than $150 \mathrm{mM} \mathrm{NaCl}$. These direct observations suggest that $\mathrm{MotS}_{\mathrm{PGB}}$ functions as a $\mathrm{Na}^{+}$sensor to efficiently promote the assembly and disassembly of the MotPS complex with the motor in response to changes in external $\mathrm{Na}^{+}$concentration [93].

\section{Conclusions and Perspectives}

The flagellum of E. coli and Salmonella is a supramolecular rotary motor powered by an inward-directed $\mathrm{H}^{+}$translocation through a transmembrane $\mathrm{H}^{+}$channel of the MotAB stator complex and can spin in both CCW and CW directions without changing the direction of $\mathrm{H}^{+}$flow. The flagellar motor is conserved among bacterial species, but the flagellar structure has adopted to function in various environments of the habitant of bacteria $[9,10]$. The structure of the rod, hook and filament and their mechanical properties are understood at near atomic resolution. Because structural information on the rotor and stator is still limited, it remains unknown how the transmembrane stator complex conducts ions and exerts force on the rotor, how the rotor switches between the CCW and CW states in a highly cooperative manner, and how the stator complex senses external ion concentration to become an active stator unit around the rotor. To clarify these remaining questions, high-resolution structural analyses of the rotor and stator would be required.

The elementary process of the flagellar motor is visualized to be composed of a step and a dwell $[135,136]$. Since the dissociation rate of the stator unit becomes much faster at low load than at high load, the number of active stator units in the motor is decreased from 10 to a few when external loads become low enough [130]. Although the duty ratio of the flagellar motor seems to be small, the flagellar motor containing only a few stator units can processively generate torque for high-speed rotation near zero load. However, it remains unknown how the $\mathrm{H}^{+}$translocation process is linked to a torque generation step by stator-rotor interactions and how cyclic association-dissociation of MotA with every FliG subunit along the circumference of the rotor allow the motor to spin at about 300 revolutions per second in a highly processive manner. Much more precise measurements of the rotational speed of the flagellar motor near zero load would be essential to advance our mechanistic understanding of the energy coupling mechanism of the flagellar motor. 
Funding: This work was supported in part by Grants-in-Aid for Scientific Research from the Japan Society for the Promotion of Science (JSPS KAKENHI Grant Numbers 18K07100 to S.N. and 19H03182 to T.M.).

Acknowledgments: We acknowledge Keiichi Namba, Seishi Kudo and Yusuke V. Morimoto for continuous support and encouragement.

Conflicts of Interest: The authors declare no conflict of interest.

\section{References}

1. Josenhans, C.; Suerbaum, S. The role of motility as a virulence factor in bacteria. Int. J. Med. Microbiol. 2002, 291, 605-614. [CrossRef] [PubMed]

2. Lertsethtakarn, P.; Ottemann, K.M.; Hendrixson, D.R. Motility and chemotaxis in Campylobacter and Helicobacter. Annu. Rev. Microbiol. 2011, 65, 389-410. [CrossRef] [PubMed]

3. Visick, K.L. An intricate network of regulators controls biofilm formation and colonization by Vibrio fischeri. Mol. Microbiol. 2009, 74, 782-789. [CrossRef] [PubMed]

4. Scharf, B.E.; Hynes, M.F.; Alexandre, G.M. Chemotaxis signaling systems in model beneficial plant-bacteria associations. Plant Mol. Biol. 2016, 90, 549-559. [CrossRef] [PubMed]

5. Ishikawa, T.; Yoshida, N.; Ueno, H.; Wiedeman, M.; Imai, Y.; Yamaguchi, T. Energy transport in a concentrated suspension of bacteria. Phys. Rev. Lett. 2011, 107, 028102. [CrossRef] [PubMed]

6. Jarrell, K.F.; McBride, M.J. The surprisingly diverse ways that prokaryotes move. Nat. Rev. Microbiol. 2008, 6, 466-476. [CrossRef] [PubMed]

7. Charon, N.W.; Goldstein, S.F. Genetics of motility and chemotaxis of a fascinating group of bacteria: The spirochetes. Annu. Rev. Genet. 2002, 36, 47-73. [CrossRef]

8. Minamino, T.; Namba, K. Self-assembly and type III protein export of the bacterial flagellum. J. Mol. Microbiol. Biotechnol. 2004, 7, 5-17. [CrossRef]

9. Terashima, H.; Kawamoto, A.; Morimoto, Y.V.; Imada, K.; Minamino, T. Structural differences in the bacterial flagellar motor among bacterial species. Biophys. Physicobiology 2017, 14, 191-198. [CrossRef]

10. Minamino, T.; Imada, K. The bacterial flagellar motor and its structural diversity. Trends Microbiol. 2015, 23, 267-274. [CrossRef]

11. Chen, X.; Berg, H.C. Torque-speed relationship of the flagellar rotary motor of Escherichia coli. Biophys. J. 2000, 78, 1036-1041. [CrossRef]

12. Magariyama, Y.; Sugiyama, S.; Muramoto, K.; Maekawa, Y.; Kawagishi, I.; Imae, Y.; Kudo, S. Very fast flagellar rotation. Nature 1994, 371, 752. [CrossRef] [PubMed]

13. Morimoto, Y.V.; Minamino, T. Structure and function of the bi-directional bacterial flagellar motor. Biomolecules 2014, 4, 217-234. [CrossRef] [PubMed]

14. Minamino, T.; Terahara, N.; Kojima, S.; Namba, K. Autonomous control mechanism of stator assembly in the bacterial flagellar motor in response to changes in the environment. Mol. Microbiol. 2018, 109, 723-734. [CrossRef] [PubMed]

15. Berg, H.C. The rotary motor of bacterial flagella. Annu. Rev. Biochem. 2003, 72, 19-54. [CrossRef] [PubMed]

16. Namba, K.; Vonderviszt, F. Molecular architecture of bacterial flagellum. Q. Rev. Biophys. 1997, 30, 1-65. [CrossRef]

17. Bonifield, H.R.; Hughes, K.T. Flagellar phase variation in Salmonella enterica is mediated by a posttranscriptional control mechanism. J. Bacteriol. 2003, 185, 3567-3574. [CrossRef]

18. Samatey, F.A.; Imada, K.; Nagashima, S.; Vonderviszt, F.; Kumasaka, T.; Yamamoto, M.; Namba, K. Structure of the bacterial flagellar protofilament and implications for a switch for supercoiling. Nature 2001, 410, 331-337. [CrossRef]

19. Yonekura, K.; Maki-Yonekura, S.; Namba, K. Complete atomic model of the bacterial flagellar filament by electron cryomicroscopy. Nature 2003, 424, 643-650. [CrossRef]

20. Maki-Yonekura, S.; Yonekura, K.; Namba, K. Conformational change of flagellin for polymorphic supercoiling of the flagellar filament. Nat. Struct. Mol. Biol. 2010, 17, 417-422. [CrossRef]

21. Beatson, S.A.; Minamino, T.; Pallen, M.J. Variation in bacterial flagellins: from sequence to structure. Trends Microbiol. 2006, 14, 151-155. [CrossRef] [PubMed]

22. Asakura, S. Polymerization of flagellin and polymorphism of flagella. Adv. Biophys. 1970, 1, 99-155. [PubMed] 
23. Kamiya, R.; Asakura, S.; Wakabayashi, K.; Namba, K. Transition of bacterial flagella from helical to straight forms with different subunit arrangements. J. Mol. Biol. 1979, 131, 725-742. [CrossRef]

24. Yamashita, I.; Hasegawa, K.; Suzuki, H.; Vonderviszt, F.; Mimori-Kiyosue, Y.; Namba, K. Structure and switching of bacterial flagellar filaments studied by X-ray fiber diffraction. Nat. Struct. Biol. 1998, 5, 125-132. [CrossRef] [PubMed]

25. Wang, F.; Burrage, A.M.; Postel, S.; Clark, R.E.; Orlova, A.; Sundberg, E.J.; Kearns, D.B.; Egelman, E.H. A structural model of flagellar filament switching across multiple bacterial species. Nat. Commun. 2017, 8, 960. [CrossRef] [PubMed]

26. Faulds-Pain, A.; Birchall, C.; Aldridge, C.; Smith, W.D.; Grimaldi, G.; Nakamura, S.; Miyata, T.; Gray, J.; Li, G.; Tang, J.X.; et al. Flagellin redundancy in Caulobacter crescentus and its implications for flagellar filament assembly. J. Bacteriol. 2011, 193, 2695-2707. [CrossRef] [PubMed]

27. Scharf, B.; Schuster-Wolff-Bühring, H.; Rachel, R.; Schmitt, R. Mutational Analysis of the Rhizobium lupini H13-3 andSinorhizobium meliloti Flagellin Genes: Importance of Flagellin A for Flagellar Filament Structure and Transcriptional Regulation. J. Bacteriol. 2001, 183, 5334-5342. [CrossRef] [PubMed]

28. Tambalo, D.D.; Bustard, D.E.; Del Bel, K.L.; Koval, S.F.; Khan, M.F.; Hynes, M.F. Characterization and functional analysis of seven flagellin genes in Rhizobium leguminosarum bv. viciae. Characterization of $\mathrm{R}$. leguminosarum flagellins. BMC Microbiol. 2010, 10, 219. [CrossRef]

29. Mohari, B.; Thompson, M.A.; Trinidad, J.C.; Setayeshgar, S.; Fuqua, C. Multiple Flagellin Proteins Have Distinct and Synergistic Roles in Agrobacterium tumefaciens Motility. J. Bacteriol. 2018, 200, e00327-18. [CrossRef]

30. Quelas, J.I.; Althabegoiti, M.J.; Jimenez-Sanchez, C.; Melgarejo, A.A.; Marconi, V.I.; Mongiardini, E.J.; Trejo, S.A.; Mengucci, F.; Ortega-Calvo, J.-J.; Lodeiro, A.R. Swimming performance of Bradyrhizobium diazoefficiens is an emergent property of its two flagellar systems. Sci. Rep. 2016, 6, 23841. [CrossRef]

31. Inoue, T.; Barker, C.S.; Matsunami, H.; Aizawa, S.-I.; Samatey, F.A. The FlaG regulator is involved in length control of the polar flagella of Campylobacter jejuni. Microbiology 2018, 164, 740-750. [CrossRef] [PubMed]

32. Kühn, M.J.; Schmidt, F.K.; Farthing, N.E.; Rossmann, F.M.; Helm, B.; Wilson, L.G.; Eckhardt, B.; Thormann, K.M. Spatial arrangement of several flagellins within bacterial flagella improves motility in different environments. Nat. Commun. 2018, 9, 5369. [CrossRef] [PubMed]

33. Lambert, C.; Evans, K.J.; Till, R.; Hobley, L.; Capeness, M.; Rendulic, S.; Schuster, S.C.; Aizawa, S.-I.; Sockett, R.E. Characterizing the flagellar filament and the role of motility in bacterial prey-penetration by Bdellovibrio bacteriovorus. Mol. Microbiol. 2006, 60, 274-286. [CrossRef] [PubMed]

34. Kim, S.Y.; Thanh, X.T.T.; Jeong, K.; Kim, S.B.; Pan, S.O.; Jung, C.H.; Hong, S.H.; Lee, S.E.; Rhee, J.H. Contribution of six flagellin genes to the flagellum biogenesis of Vibrio vulnificus and in vivo invasion. Infect. Immun. 2014, 82, 29-42. [CrossRef] [PubMed]

35. Ikeda, J.S.; Schmitt, C.K.; Darnell, S.C.; Watson, P.R.; Bispham, J.; Wallis, T.S.; Weinstein, D.L.; Metcalf, E.S.; Adams, P.; O'Connor, C.D.; et al. Flagellar phase variation of Salmonella enterica serovar Typhimurium contributes to virulence in the murine typhoid infection model but does not influence Salmonella-induced enteropathogenesis. Infect. Immun. 2001, 69, 3021-3030. [CrossRef] [PubMed]

36. Samatey, F.A.; Matsunami, H.; Imada, K.; Nagashima, S.; Shaikh, T.R.; Thomas, D.R.; Chen, J.Z.; Derosier, D.J.; Kitao, A.; Namba, K. Structure of the bacterial flagellar hook and implication for the molecular universal joint mechanism. Nature 2004, 431, 1062-1068. [CrossRef]

37. Fujii, T.; Kato, T.; Namba, K. Specific arrangement of $\alpha$-helical coiled coils in the core domain of the bacterial flagellar hook for the universal joint function. Structure 2009, 17, 1485-1493. [CrossRef]

38. Sakai, T.; Inoue, Y.; Terahara, N.; Namba, K.; Minamino, T. A triangular loop of domain D1 of FlgE is essential for hook assembly but not for the mechanical function. Biochem. Biophys. Res. Commun. 2018, 495, 1789-1794. [CrossRef]

39. Fujii, T.; Matsunami, H.; Inoue, Y.; Namba, K. Evidence for the hook supercoiling mechanism of the bacterial flagellum. Biophys. Physicobiology 2018, 15, 28-32. [CrossRef]

40. Matsunami, H.; Barker, C.S.; Yoon, Y.-H.; Wolf, M.; Samatey, F.A. Complete structure of the bacterial flagellar hook reveals extensive set of stabilizing interactions. Nat. Commun. 2016, 7, 13425. [CrossRef]

41. Brown, M.T.; Steel, B.C.; Silvestrin, C.; Wilkinson, D.A.; Delalez, N.J.; Lumb, C.N.; Obara, B.; Armitage, J.P.; Berry, R.M. Flagellar hook flexibility is essential for bundle formation in swimming Escherichia coli cells. J. Bacteriol. 2012, 194, 3495-3501. [CrossRef] [PubMed] 
42. Hiraoka, K.D.; Morimoto, Y.V.; Inoue, Y.; Fujii, T.; Miyata, T.; Makino, F.; Minamino, T.; Namba, K. Straight and rigid flagellar hook made by insertion of the FlgG specific sequence into FlgE. Sci. Rep. 2017, 7, 46723. [CrossRef] [PubMed]

43. Spöring, I.; Martinez, V.A.; Hotz, C.; Schwarz-Linek, J.; Grady, K.L.; Nava-Sedeño, J.M.; Vissers, T.; Singer, H.M.; Rohde, M.; Bourquin, C.; et al. Hook length of the bacterial flagellum is optimized for maximal stability of the flagellar bundle. PLoS Biol. 2018, 16, e2006989. [CrossRef] [PubMed]

44. Minamino, T. Hierarchical protein export mechanism of the bacterial flagellar type III protein export apparatus. FEMS Microbiol. Lett. 2018, 365, fny117. [CrossRef] [PubMed]

45. Son, K.; Guasto, J.S.; Stocker, R. Bacteria can exploit a flagellar buckling instability to change direction. Nat. Phys. 2013, 9, 494-498. [CrossRef]

46. Homma, M.; Kutsukake, K.; Hasebe, M.; Iino, T.; Macnab, R.M. FlgB, FlgC, FlgF and FlgG: A family of structurally related proteins in the flagellar basal body of Salmonella typhimurium. J. Mol. Biol. 1990, 211, 465-477. [CrossRef]

47. Kubori, T.; Shimamoto, N.; Yamaguchi, S.; Namba, K.; Aizawa, S.-I. Morphological pathway of flagellar assembly in Salmonella typhimurium. J. Mol. Biol. 1992, 226, 433-446. [CrossRef]

48. Minamino, T.; Yamaguchi, S.; Macnab, R.M. Interaction between FliE and FlgB, a proximal rod component of the flagellar basal body of Salmonella. J. Bacteriol. 2000, 182, 3029-3036. [CrossRef]

49. Fujii, T.; Kato, T.; Hiraoka, K.D.; Miyata, T.; Minamino, T.; Chevance, F.F.V.; Hughes, K.T.; Namba, K. Identical folds used for distinct mechanical functions of the bacterial flagellar rod and hook. Nat. Commun. 2017, 8, 14276. [CrossRef]

50. Minamino, T. Protein export through the bacterial flagellar type III export pathway. Biochim. Biophys. Acta 2014, 1843, 1642-1648. [CrossRef]

51. Minamino, T.; Macnab, R.M. Components of the Salmonella flagellar export apparatus and classification of export substrates. J. Bacteriol. 1999, 181, 1388-1394. [PubMed]

52. Fukumura, T.; Makino, F.; Dietsche, T.; Kinoshita, M.; Kato, T.; Wagner, S.; Namba, K.; Imada, K.; Minamino, T. Assembly and stoichiometry of the core structure of the bacterial flagellar type III export gate complex. PLoS Biol. 2017, 15, e2002281. [CrossRef] [PubMed]

53. Minamino, T.; Macnab, R.M. Interactions among components of the Salmonella flagellar export apparatus and its substrates. Mol. Microbiol. 2000, 35, 1052-1064. [CrossRef] [PubMed]

54. Minamino, T.; Morimoto, Y.V.; Hara, N.; Namba, K. An energy transduction mechanism used in bacterial flagellar type III protein export. Nat. Commun. 2011, 2, 475. [CrossRef] [PubMed]

55. Morimoto, Y.V.; Kami-ike, N.; Miyata, T.; Kawamoto, A.; Kato, T.; Namba, K.; Minamino, T. High-resolution $\mathrm{pH}$ imaging of living bacterial cells to detect local $\mathrm{pH}$ differences. mBio 2016, 7, e01911-16. [CrossRef] [PubMed]

56. Fabiani, F.D.; Renault, T.T.; Peters, B.; Dietsche, T.; Gálvez, E.J.C.; Guse, A.; Freier, K.; Charpentier, E.; Strowig, T.; Franz-Wachtel, M.; et al. A flagellum-specific chaperone facilitates assembly of the core type III export apparatus of the bacterial flagellum. PLoS Biol. 2017, 15, e2002267. [CrossRef] [PubMed]

57. Kuhlen, L.; Abrusci, P.; Johnson, S.; Gault, J.; Deme, J.; Caesar, J.; Dietsche, T.; Mebrhatu, M.T.; Ganief, T.; Macek, B.; et al. Structure of the core of the type III secretion system export apparatus. Nat. Struct. Mol. Biol. 2018, 25, 583-590. [CrossRef] [PubMed]

58. Dietsche, T.; Tesfazgi Mebrhatu, M.; Brunner, M.J.; Abrusci, P.; Yan, J.; Franz-Wachtel, M.; Schärfe, C.; Zilkenat, S.; Grin, I.; Galán, J.E.; et al. Structural and functional characterization of the bacterial type III secretion export apparatus. PLoS Pathog. 2016, 12, e1006071. [CrossRef]

59. Abrusci, P.; Vergara-Irigaray, M.; Johnson, S.; Beeby, M.D.; Hendrixson, D.R.; Roversi, P.; Friede, M.E.; Deane, J.E.; Jensen, G.J.; Tang, C.M.; et al. Architecture of the major component of the type III secretion system export apparatus. Nat. Struct. Mol. Biol. 2013, 20, 99-104. [CrossRef]

60. Kawamoto, A.; Morimoto, Y.V.; Miyata, T.; Minamino, T.; Hughes, K.T.; Kato, T.; Namba, K. Common and distinct structural features of Salmonella injectisome and flagellar basal body. Sci. Rep. 2013, 3, 3369. [CrossRef]

61. Terahara, N.; Inoue, Y.; Kodera, N.; Morimoto, Y.V.; Uchihashi, T.; Imada, K.; Ando, T.; Namba, K.; Minamino, T. Insight into structural remodeling of the FlhA ring responsible for bacterial flagellar type III protein export. Sci. Adv. 2018, 4, eaao7054. [CrossRef] [PubMed] 
62. Minamino, T.; Morimoto, Y.V.; Hara, N.; Aldridge, P.D.; Namba, K. The bacterial flagellar type III export gate complex is a dual fuel engine that can use both $\mathrm{H}^{+}$and $\mathrm{Na}^{+}$for flagellar protein export. PLoS Pathog. 2016, 12, e1005495. [CrossRef] [PubMed]

63. Imada, K.; Minamino, T.; Tahara, A.; Namba, K. Structural similarity between the flagellar type III ATPase FliI and F1-ATPase subunits. Proc. Natl. Acad. Sci. USA 2007, 104, 485-490. [CrossRef] [PubMed]

64. Ibuki, T.; Imada, K.; Minamino, T.; Kato, T.; Miyata, T.; Namba, K. Common architecture of the flagellar type III protein export apparatus and F- and V-type ATPases. Nat. Struct. Mol. Biol. 2011, 18, 277-282. [CrossRef] [PubMed]

65. Imada, K.; Minamino, T.; Uchida, Y.; Kinoshita, M.; Namba, K. Insight into the flagella type III export revealed by the complex structure of the type III ATPase and its regulator. Proc. Natl. Acad. Sci. USA 2016, 113, 3633-3638. [CrossRef] [PubMed]

66. Gonzalez-Pedrajo, B.; Minamino, T.; Kihara, M.; Namba, K. Interactions between C ring proteins and export apparatus components: A possible mechanism for facilitating type III protein export. Mol. Microbiol. 2006, 60, 984-998. [CrossRef] [PubMed]

67. Minamino, T.; Yoshimura, S.D.J.; Morimoto, Y.V.; GonzÃ jlez-Pedrajo, B.; Kami-ike, N.; Namba, K. Roles of the extreme N-terminal region of FliH for efficient localization of the FliH-FliI complex to the bacterial flagellar type III export apparatus: Localization of Salmonella FliH-FliI complex. Mol. Microbiol. 2009, 74, 1471-1483. [CrossRef] [PubMed]

68. Hara, N.; Morimoto, Y.V.; Kawamoto, A.; Namba, K.; Minamino, T. Interaction of the extreme N-terminal region of FliH with FlhA is required for efficient bacterial flagellar protein export. J. Bacteriol. 2012, 194, 5353-5360. [CrossRef]

69. Bai, F.; Morimoto, Y.V.; Yoshimura, S.D.J.; Hara, N.; Kami-ike, N.; Namba, K.; Minamino, T. Assembly dynamics and the roles of FliI ATPase of the bacterial flagellar export apparatus. Sci. Rep. 2014, 4, 6528. [CrossRef]

70. Minamino, T.; Morimoto, Y.V.; Kinoshita, M.; Aldridge, P.D.; Namba, K. The bacterial flagellar protein export apparatus processively transports flagellar proteins even with extremely infrequent ATP hydrolysis. Sci. Rep. 2014, 4, 7579. [CrossRef]

71. Minamino, T.; Imada, K.; Namba, K. Molecular motors of the bacterial flagella. Curr. Opin. Struct. Biol. 2008, 18, 693-701. [CrossRef] [PubMed]

72. Lynch, M.J.; Levenson, R.; Kim, E.A.; Sircar, R.; Blair, D.F.; Dahlquist, F.W.; Crane, B.R. Co-folding of a FliF-FliG split domain forms the basis of the MS:C ring interface within the bacterial flagellar motor. Structure 2017, 25, 317-328. [CrossRef] [PubMed]

73. Baker, M.A.B.; Hynson, R.M.G.; Ganuelas, L.A.; Mohammadi, N.S.; Liew, C.W.; Rey, A.A.; Duff, A.P.; Whitten, A.E.; Jeffries, C.M.; Delalez, N.J.; et al. Domain-swap polymerization drives the self-assembly of the bacterial flagellar motor. Nat. Struct. Mol. Biol. 2016, 23, 197-203. [CrossRef] [PubMed]

74. Kim, E.A.; Panushka, J.; Meyer, T.; Ide, N.; Carlisle, R.; Baker, S.; Blair, D.F. Biogenesis of the flagellar switch complex in Escherichia coli: Formation of sub-complexes independently of the basal-body MS-ring. J. Mol. Biol. 2017, 429, 2353-2359. [CrossRef] [PubMed]

75. Kinoshita, M.; Furukawa, Y.; Uchiyama, S.; Imada, K.; Namba, K.; Minamino, T. Insight into adaptive remodeling of the rotor ring complex of the bacterial flagellar motor. Biochem. Biophys. Res. Commun. 2018, 496, 12-17. [CrossRef] [PubMed]

76. Kinoshita, M.; Namba, K.; Minamino, T. Effect of a clockwise-locked deletion in FliG on the FliG ring structure of the bacterial flagellar motor. Genes Cells 2018, 23, 241-247. [CrossRef] [PubMed]

77. Zhou, J.; Lloyd, S.A.; Blair, D.F. Electrostatic interactions between rotor and stator in the bacterial flagellar motor. Proc. Natl. Acad. Sci. USA 1998, 95, 6436-6441. [CrossRef]

78. Morimoto, Y.V.; Nakamura, S.; Kami-ike, N.; Namba, K.; Minamino, T. Charged residues in the cytoplasmic loop of MotA are required for stator assembly into the bacterial flagellar motor. Mol. Microbiol. 2010, 78, 1117-1129. [CrossRef]

79. Morimoto, Y.V.; Nakamura, S.; Hiraoka, K.D.; Namba, K.; Minamino, T. Distinct roles of highly conserved charged residues at the MotA-FliG interface in bacterial flagellar motor rotation. J. Bacteriol. 2013, 195, 474-481. [CrossRef]

80. Paul, K.; Gonzalez-Bonet, G.; Bilwes, A.M.; Crane, B.R.; Blair, D. Architecture of the flagellar rotor. EMBO J. 2011, 30, 2962-2971. [CrossRef] 
81. McDowell, M.A.; Marcoux, J.; McVicker, G.; Johnson, S.; Fong, Y.H.; Stevens, R.; Bowman, L.A.H.; Degiacomi, M.T.; Yan, J.; Wise, A.; et al. Characterisation of Shigella Spa33 and Thermotoga FliM/N reveals a new model for C-ring assembly in T3SS: Uniform C-ring assembly by NF- and flagellar-T3SS. Mol. Microbiol. 2016, 99, 749-766. [CrossRef] [PubMed]

82. Ward, E.; Kim, E.A.; Panushka, J.; Botelho, T.; Meyer, T.; Kearns, D.B.; Ordal, G.; Blair, D.F. Organization of the flagellar switch complex of Bacillus subtilis. J. Bacteriol. 2019, 201, e00626-18. [CrossRef] [PubMed]

83. Delalez, N.J.; Wadhams, G.H.; Rosser, G.; Xue, Q.; Brown, M.T.; Dobbie, I.M.; Berry, R.M.; Leake, M.C.; Armitage, J.P. Signal-dependent turnover of the bacterial flagellar switch protein FliM. Proc. Natl. Acad. Sci. USA 2010, 107, 11347-11351. [CrossRef] [PubMed]

84. Delalez, N.J.; Berry, R.M.; Armitage, J.P. Stoichiometry and turnover of the bacterial flagellar switch protein FliN. mBio 2014, 5, e01216-14. [CrossRef] [PubMed]

85. Branch, R.W.; Sayegh, M.N.; Shen, C.; Nathan, V.S.J.; Berg, H.C. Adaptive remodelling by FliN in the bacterial rotary motor. J. Mol. Biol. 2014, 426, 3314-3324. [CrossRef] [PubMed]

86. Pourjaberi, S.N.S.; Terahara, N.; Namba, K.; Minamino, T. The role of a cytoplasmic loop of MotA in load-dependent assembly and disassembly dynamics of the MotA/B stator complex in the bacterial flagellar motor. Mol. Microbiol. 2017, 106, 646-658. [CrossRef] [PubMed]

87. Sakai, T.; Miyata, T.; Terahara, N.; Mori, K.; Inoue, Y.; Morimoto, Y.V.; Kato, T.; Namba, K.; Minamino, T. Novel insights into conformational rearrangements of the bacterial flagellar switch complex. mBio 2019, 10, e00079-19. [CrossRef] [PubMed]

88. Beeby, M.; Ribardo, D.A.; Brennan, C.A.; Ruby, E.G.; Jensen, G.J.; Hendrixson, D.R. Diverse high-torque bacterial flagellar motors assemble wider stator rings using a conserved protein scaffold. Proc. Natl. Acad. Sci. USA 2016, 113, E1917-E1926. [CrossRef] [PubMed]

89. Kojima, S.; Blair, D.F. Solubilization and purification of the MotA/MotB complex of Escherichia coli. Biochemistry 2004, 43, 26-34. [CrossRef] [PubMed]

90. Braun, T.F.; Al-Mawsawi, L.Q.; Kojima, S.; Blair, D.F. Arrangement of core membrane segments in the MotA/MotB proton-channel complex of Escherichia coli. Biochemistry 2004, 43, 35-45. [CrossRef] [PubMed]

91. Sato, K.; Homma, M. Multimeric structure of PomA, a component of the $\mathrm{Na}^{+}$-driven polar flagellar motor of Vibrio alginolyticus. J. Biol. Chem. 2000, 275, 20223-20228. [CrossRef] [PubMed]

92. Ito, M.; Hicks, D.B.; Henkin, T.M.; Guffanti, A.A.; Powers, B.D.; Zvi, L.; Uematsu, K.; Krulwich, T.A. MotPS is the stator-force generator for motility of alkaliphilic Bacillus, and its homologue is a second functional Mot in Bacillus subtilis: Alkaliphile MotPS and its B. subtilis homologue. Mol. Microbiol. 2004, 53, 1035-1049. [CrossRef] [PubMed]

93. Terahara, N.; Kodera, N.; Uchihashi, T.; Ando, T.; Namba, K.; Minamino, $\mathrm{T} . \mathrm{Na}^{+}$-induced structural transition of MotPS for stator assembly of the Bacillus flagellar motor. Sci. Adv. 2017, 3, eaao4119. [CrossRef] [PubMed]

94. Eggenhofer, E.; Haslbeck, M.; Scharf, B. MotE serves as a new chaperone specific for the periplasmic motility protein, MotC, in Sinorhizobium meliloti. Mol. Microbiol. 2004, 52, 701-712. [CrossRef] [PubMed]

95. Terashima, H.; Fukuoka, H.; Yakushi, T.; Kojima, S.; Homma, M. The Vibrio motor proteins, MotX and MotY, are associated with the basal body of $\mathrm{Na}^{+}$-driven flagella and required for stator formation. Mol. Microbiol. 2006, 62, 1170-1180. [CrossRef] [PubMed]

96. McCarter, L.; Silverman, M. Surface-induced swarmer cell differentiation of Vibrio parahaemoiyticus. Mol. Microbiol. 1990, 4, 1057-1062. [CrossRef] [PubMed]

97. McCarter, L.; Hilmen, M.; Silverman, M. Flagellar dynamometer controls swarmer cell differentiation of V. parahaemolyticus. Cell 1988, 54, 345-351. [CrossRef]

98. Kawagishi, I.; Imagawa, M.; Imae, Y.; McCarter, L.; Homma, M. The sodium-driven polar flagellar motor of marine Vibrio as the mechanosensor that regulates lateral flagellar expression. Mol. Microbiol. 1996, 20, 693-699. [CrossRef]

99. Kawagishi, I.; Maekawa, Y.; Atsumi, T.; Homma, M.; Imae, Y. Isolation of the polar and lateral flagellum-defective mutants in Vibrio alginolyticus and identification of their flagellar driving energy sources. J. Bacteriol. 1995, 177, 5158-5160. [CrossRef]

100. Ito, M.; Terahara, N.; Fujinami, S.; Krulwich, T.A. Properties of motility in Bacillus subtilis powered by the $\mathrm{H}^{+}$-coupled MotAB flagellar stator, $\mathrm{Na}^{+}$-coupled MotPS or hybrid stators MotAS or MotPB. J. Mol. Biol. 2005, 352, 396-408. [CrossRef] 
101. Paulick, A.; Koerdt, A.; Lassak, J.; Huntley, S.; Wilms, I.; Narberhaus, F.; Thormann, K.M. Two different stator systems drive a single polar flagellum in Shewanella oneidensis MR-1. Mol. Microbiol. 2009, 71, 836-850. [CrossRef] [PubMed]

102. Terahara, N.; Sano, M.; Ito, M. A Bacillus flagellar motor that can use both $\mathrm{Na}^{+}$and $\mathrm{K}^{+}$as a coupling ion is converted by a single mutation to use only $\mathrm{Na}^{+}$. PLoS ONE 2012, 7, e46248. [CrossRef] [PubMed]

103. Terahara, N.; Krulwich, T.A.; Ito, M. Mutations alter the sodium versus proton use of a Bacillus clausii flagellar motor and confer dual ion use on Bacillus subtilis motors. Proc. Natl. Acad. Sci. USA 2008, 105, 14359-14364. [CrossRef] [PubMed]

104. Islam, M.S.; Morimoto, Y.V.; Kudo, S.; Nakamura, S. $\mathrm{H}^{+}$and $\mathrm{Na}^{+}$are involved in flagellar rotation of the spirochete Leptospira. Biochem. Biophys. Res. Commun. 2015, 466, 196-200. [CrossRef] [PubMed]

105. Nishihara, Y.; Kitao, A. Gate-controlled proton diffusion and protonation-induced ratchet motion in the stator of the bacterial flagellar motor. Proc. Natl. Acad. Sci. USA 2015, 112, 7737-7742. [CrossRef] [PubMed]

106. Zhou, J.; Sharp, L.L.; Tang, H.L.; Lloyd, S.A.; Billings, S.; Braun, T.F.; Blair, D.F. Function of protonatable residues in the flagellar motor of Escherichia coli: A sritical role for Asp 32 of MotB. J. Bacteriol. 1998, 180, 2729-2735.

107. Morimoto, Y.V.; Che, Y.-S.; Minamino, T.; Namba, K. Proton-conductivity assay of plugged and unplugged MotA/B proton channel by cytoplasmic pHluorin expressed in Salmonella. FEBS Lett. 2018, 584, 1268-1272. [CrossRef]

108. Hosking, E.R.; Vogt, C.; Bakker, E.P.; Manson, M.D. The Escherichia coli MotAB proton channel unplugged. J. Mol. Biol. 2006, 364, 921-937. [CrossRef]

109. Minamino, T.; Imae, Y.; Oosawa, F.; Kobayashi, Y.; Oosawa, K. Effect of intracellular pH on rotational speed of bacterial flagellar motors. J. Bacteriol. 2003, 185, 1190-1194. [CrossRef]

110. Nakamura, S.; Kami-ike, N.; Yokota, J.P.; Kudo, S.; Minamino, T.; Namba, K. Effect of intracellular pH on the torque-speed relationship of bacterial proton-driven flagellar motor. J. Mol. Biol. 2009, 386, 332-338. [CrossRef]

111. Che, Y.-S.; Nakamura, S.; Kojima, S.; Kami-ike, N.; Namba, K.; Minamino, T. Suppressor analysis of the $\operatorname{MotB}(\mathrm{D} 33 \mathrm{E})$ mutation to probe bacterial flagellar motor dynamics coupled with proton translocation. J. Bacteriol. 2008, 190, 6660-6667. [CrossRef] [PubMed]

112. Che, Y.-S.; Nakamura, S.; Morimoto, Y.V.; Kami-Ike, N.; Namba, K.; Minamino, T. Load-sensitive coupling of proton translocation and torque generation in the bacterial flagellar motor. Mol. Microbiol. 2014, 91, 175-184. [CrossRef] [PubMed]

113. Nakamura, S.; Morimoto, Y.V.; Kami-ike, N.; Minamino, T.; Namba, K. Role of a conserved prolyl residue (Pro173) of MotA in the mechanochemical reaction cycle of the proton-driven flagellar motor of Salmonella. J. Mol. Biol. 2009, 393, 300-307. [CrossRef] [PubMed]

114. Kim, E.A.; Price-Carter, M.; Carlquist, W.C.; Blair, D.F. Membrane segment organization in the stator complex of the flagellar motor: Implications for proton flow and proton-induced conformational change. Biochemistry 2008, 47, 11332-11339. [CrossRef] [PubMed]

115. Braun, T.F.; Poulson, S.; Gully, J.B.; Empey, J.C.; Van Way, S.; Putnam, A.; Blair, D.F. Function of proline residues of MotA in torque generation by the flagellar motor of Escherichia coli. J. Bacteriol. 1999, 181, 3542-3551.

116. Sudo, Y.; Terashima, H.; Abe-Yoshizumi, R.; Kojima, S.; Homma, M. Comparative study of the ion flux pathway in stator units of proton- and sodium-driven flagellar motors. Biophysics 2009, 5, 45-52. [CrossRef] [PubMed]

117. Sharp, L.L.; Zhou, J.; Blair, D.F. Features of MotA proton channel structure revealed by tryptophan-scanning mutagenesis. Proc. Natl. Acad. Sci. USA 1995, 92, 7946-7950. [CrossRef]

118. Suzuki, Y.; Morimoto, Y.V.; Oono, K.; Hayashi, F.; Oosawa, K.; Kudo, S.; Nakamura, S. Effect of the $\operatorname{MotA}(\mathrm{M} 206 \mathrm{I})$ mutation on torque generation and stator assembly in the Salmonella $\mathrm{H}^{+}$-driven flagellar motor. J. Bacteriol. 2019, 201, e00727-18. [CrossRef]

119. Kojima, S.; Blair, D.F. Conformational change in the stator of the bacterial flagellar motor. Biochemistry 2001, 40, 13041-13050. [CrossRef]

120. Zhou, J.; Blair, D.F. Residues of the cytoplasmic domain of MotA essential for torque generation in the bacterial flagellar motor. J. Mol. Biol. 1997, 273, 428-439. [CrossRef]

121. Silverman, M.; Simon, M. Flagellar rotation and the mechanism of bacterial motility. Nature 1974, $249,73-74$. [CrossRef] [PubMed] 
122. Ryu, W.S.; Berry, R.M.; Berg, H.C. Torque-generating units of the flagellar motor of Escherichia coli have a high duty ratio. Nature 2000, 403, 444-447. [CrossRef] [PubMed]

123. Chen, X.; Berg, H.C. Solvent-isotope and $\mathrm{pH}$ effects on flagellar rotation in Escherichia coli. Biophys. J. 2000, 78, 2280-2284. [CrossRef]

124. Magariyama, Y.; Sugiyama, S.; Muramoto, K.; Kawagishi, I.; Imae, Y.; Kudo, S. Simultaneous measurement of bacterial flagellar rotation rate and swimming speed. Biophys. J. 1995, 69, 2154-2162. [CrossRef]

125. Sowa, Y.; Hotta, H.; Homma, M.; Ishijima, A. Torque-speed relationship of the $\mathrm{Na}^{+}$-driven flagellar motor of Vibrio alginolyticus. J. Mol. Biol. 2003, 327, 1043-1051. [CrossRef]

126. Gabel, C.V.; Berg, H.C. The speed of the flagellar rotary motor of Escherichia coli varies linearly with protonmotive force. Proc. Natl. Acad. Sci. USA 2003, 100, 8748-8751. [CrossRef] [PubMed]

127. Lo, C.-J.; Sowa, Y.; Pilizota, T.; Berry, R.M. Mechanism and kinetics of a sodium-driven bacterial flagellar motor. Proc. Natl. Acad. Sci. USA 2013, 110, E2544-E2551. [CrossRef] [PubMed]

128. Yuan, J.; Berg, H.C. Resurrection of the flagellar rotary motor near zero load. Proc. Natl. Acad. Sci. USA 2008, 105, 1182-1185. [CrossRef]

129. Wang, B.; Zhang, R.; Yuan, J. Limiting (zero-load) speed of the rotary motor of Escherichia coli is independent of the number of torque-generating units. Proc. Natl. Acad. Sci. USA 2017, 114, 12478-12482. [CrossRef]

130. Nord, A.L.; Sowa, Y.; Steel, B.C.; Lo, C.-J.; Berry, R.M. Speed of the bacterial flagellar motor near zero load depends on the number of stator units. Proc. Natl. Acad. Sci. USA 2017, 114, 11603-11608. [CrossRef]

131. Sato, K.; Nakamura, S.; Kudo, S.; Toyabe, S. Evaluation of the duty ratio of the bacterial flagellar motor by dynamic load control. Biophys. J. 2019, 116, 1952-1959. [CrossRef] [PubMed]

132. Nishiyama, M.; Higuchi, H.; Ishii, Y.; Taniguchi, Y.; Yanagida, T. Single molecule processes on the stepwise movement of ATP-driven molecular motors. Biosystems 2003, 71, 145-156. [CrossRef]

133. Komori, Y.; Iwane, A.H.; Yanagida, T. Myosin-V makes two brownian $90^{\circ}$ rotations per 36-nm step. Nat. Struct. Mol. Biol. 2007, 14, 968-973. [CrossRef] [PubMed]

134. Adachi, K.; Oiwa, K.; Nishizaka, T.; Furuike, S.; Noji, H.; Itoh, H.; Yoshida, M.; Kinosita, K. Coupling of rotation and catalysis in $\mathrm{F}_{1}$-ATPase revealed by single-molecule imaging and manipulation. Cell 2007, 130, 309-321. [CrossRef] [PubMed]

135. Sowa, Y.; Rowe, A.D.; Leake, M.C.; Yakushi, T.; Homma, M.; Ishijima, A.; Berry, R.M. Direct observation of steps in rotation of the bacterial flagellar motor. Nature 2005, 437, 916-919. [CrossRef] [PubMed]

136. Nakamura, S.; Kami-ike, N.; Yokota, J.P.; Minamino, T.; Namba, K. Evidence for symmetry in the elementary process of bidirectional torque generation by the bacterial flagellar motor. Proc. Natl. Acad. Sci. USA 2010, 107, 17616-17620. [CrossRef] [PubMed]

137. Xing, J.; Bai, F.; Berry, R.; Oster, G. Torque-speed relationship of the bacterial flagellar motor. Proc. Natl. Acad. Sci. USA 2006, 103, 1260-1265. [CrossRef]

138. Bai, F.; Lo, C.-J.; Berry, R.M.; Xing, J. Model studies of the dynamics of bacterial flagellar motors. Biophys. J. 2009, 96, 3154-3167. [CrossRef]

139. Meacci, G.; Tu, Y. Dynamics of the bacterial flagellar motor with multiple stators. Proc. Natl. Acad. Sci. USA 2009, 106, 3746-3751. [CrossRef]

140. Bai, F.; Minamino, T.; Wu, Z.; Namba, K.; Xing, J. Coupling between switching regulation and torque generation in bacterial flagellar motor. Phys. Rev. Lett. 2012, 108, 178105. [CrossRef]

141. Mora, T.; Yu, H.; Sowa, Y.; Wingreen, N.S. Steps in the bacterial flagellar motor. PLoS Comput. Biol. 2009, 5, e1000540. [CrossRef] [PubMed]

142. Nirody, J.A.; Berry, R.M.; Oster, G. The limiting speed of the bacterial flagellar motor. Biophys. J. 2016, 111, 557-564. [CrossRef] [PubMed]

143. Briegel, A.; Ortega, D.R.; Tocheva, E.I.; Wuichet, K.; Li, Z.; Chen, S.; Muller, A.; Iancu, C.V.; Murphy, G.E.; Dobro, M.J.; et al. Universal architecture of bacterial chemoreceptor arrays. Proc. Natl. Acad. Sci. USA 2009, 106, 17181-17186. [CrossRef] [PubMed]

144. Cluzel, P. An ultrasensitive bacterial motor revealed by monitoring signaling proteins in single cells. Science 2000, 287, 1652-1655. [CrossRef] [PubMed]

145. Sourjik, V.; Berg, H.C. Binding of the Escherichia coli response regulator CheY to its target measured in vivo by fluorescence resonance energy transfer. Proc. Natl. Acad. Sci. USA 2002, 99, 12669-12674. [CrossRef] [PubMed] 
146. Sagi, Y.; Khan, S.; Eisenbach, M. Binding of the chemotaxis response regulator CheY to the isolated, intact switch complex of the bacterial flagellar motor: Lack of cooperativity. J. Biol. Chem. 2003, 278, 25867-25871. [CrossRef]

147. Lam, K.-H.; Ip, W.-S.; Lam, Y.-W.; Chan, S.-O.; Ling, T.K.-W.; Au, S.W.-N. Multiple Conformations of the FliG C-Terminal Domain Provide Insight into Flagellar Motor Switching. Structure 2012, 20, 315-325. [CrossRef]

148. Miyanoiri, Y.; Hijikata, A.; Nishino, Y.; Gohara, M.; Onoue, Y.; Kojima, S.; Kojima, C.; Shirai, T.; Kainosho, M.; Homma, M. Structural and functional analysis of the C-terminal region of FliG, an essential motor component of Vibrio $\mathrm{Na}^{+}$-driven flagella. Structure 2017, 25, 1540-1548. [CrossRef]

149. Minamino, T.; Imada, K.; Kinoshita, M.; Nakamura, S.; Morimoto, Y.V.; Namba, K. Structural insight into the rotational switching mechanism of the bacterial flagellar motor. PLoS Biol. 2011, 9, e1000616. [CrossRef]

150. Paul, K.; Brunstetter, D.; Titen, S.; Blair, D.F. A molecular mechanism of direction switching in the flagellar motor of Escherichia coli. Proc. Natl. Acad. Sci. USA 2011, 108, 17171-17176. [CrossRef]

151. Szurmant, H.; Ordal, G.W. Diversity in Chemotaxis Mechanisms among the Bacteria and Archaea. Microbiol. Mol. Biol. Rev. 2004, 68, 301-319. [CrossRef] [PubMed]

152. Porter, S.L.; Wadhams, G.H.; Armitage, J.P. Rhodobacter sphaeroides: Complexity in chemotactic signalling. Trends Microbiol. 2008, 16, 251-260. [CrossRef] [PubMed]

153. Bai, F.; Branch, R.W.; Nicolau, D.V.; Pilizota, T.; Steel, B.C.; Maini, P.K.; Berry, R.M. Conformational spread as a mechanism for cooperativity in the bacterial flagellar switch. Science 2010, 327, 685-689. [CrossRef] [PubMed]

154. Fukuoka, H.; Sagawa, T.; Inoue, Y.; Takahashi, H.; Ishijima, A. Direct imaging of intracellular signaling components that regulate bacterial chemotaxis. Sci. Signal. 2014, 7, ra32. [CrossRef] [PubMed]

155. Fahrner, K.A.; Ryu, W.S.; Berg, H.C. Biomechanics: Bacterial flagellar switching under load. Nature 2003, 423, 938. [CrossRef] [PubMed]

156. Yuan, J.; Fahrner, K.A.; Berg, H.C. Switching of the bacterial flagellar motor near zero load. J. Mol. Biol. 2009, 390, 394-400. [CrossRef] [PubMed]

157. Wang, F.; Shi, H.; He, R.; Wang, R.; Zhang, R.; Yuan, J. Non-equilibrium effect in the allosteric regulation of the bacterial flagellar switch. Nat. Phys. 2017, 13, 710-714. [CrossRef]

158. Kojima, S.; Imada, K.; Sakuma, M.; Sudo, Y.; Kojima, C.; Minamino, T.; Homma, M.; Namba, K. Stator assembly and activation mechanism of the flagellar motor by the periplasmic region of MotB. Mol. Microbiol. 2009, 73, 710-718. [CrossRef] [PubMed]

159. Kojima, S.; Takao, M.; Almira, G.; Kawahara, I.; Sakuma, M.; Homma, M.; Kojima, C.; Imada, K. The helix rearrangement in the periplasmic domain of the flagellar stator B subunit activates peptidoglycan binding and ion influx. Structure 2018, 26, 590-598. [CrossRef]

160. Zhu, S.; Takao, M.; Li, N.; Sakuma, M.; Nishino, Y.; Homma, M.; Kojima, S.; Imada, K. Conformational change in the periplasmic region of the flagellar stator coupled with the assembly around the rotor. Proc. Natl. Acad. Sci. USA 2014, 111, 13523-13528. [CrossRef]

161. Reid, S.W.; Leake, M.C.; Chandler, J.H.; Lo, C.-J.; Armitage, J.P.; Berry, R.M. The maximum number of torque-generating units in the flagellar motor of Escherichia coli is at least 11. Proc. Natl. Acad. Sci. USA 2006, 103, 8066-8071. [CrossRef] [PubMed]

162. Leake, M.C.; Chandler, J.H.; Wadhams, G.H.; Bai, F.; Berry, R.M.; Armitage, J.P. Stoichiometry and turnover in single, functioning membrane protein complexes. Nature 2006, 443, 355-358. [CrossRef] [PubMed]

163. Lele, P.P.; Hosu, B.G.; Berg, H.C. Dynamics of mechanosensing in the bacterial flagellar motor. Proc. Natl. Acad. Sci. USA 2013, 110, 11839-11844. [CrossRef] [PubMed]

164. Tipping, M.J.; Delalez, N.J.; Lim, R.; Berry, R.M.; Armitage, J.P. Load-dependent assembly of the bacterial flagellar motor. mBio 2013, 4, e00551-13. [CrossRef] [PubMed]

165. Terahara, N.; Noguchi, Y.; Nakamura, S.; Kami-ike, N.; Ito, M.; Namba, K.; Minamino, T. Load- and polysaccharide-dependent activation of the $\mathrm{Na}^{+}$-type MotPS stator in the Bacillus subtilis flagellar motor. Sci. Rep. 2017, 7, 46081. [CrossRef] [PubMed]

166. Castillo, D.J.; Nakamura, S.; Morimoto, Y.V.; Che, Y.-S.; Kami-ike, N.; Kudo, S.; Minamino, T.; Namba, K. The C-terminal periplasmic domain of MotB is responsible for load-dependent control of the number of stators of the bacterial flagellar motor. Biophysics 2013, 9, 173-181. [CrossRef]

167. Shi, H.; Ma, S.; Zhang, R.; Yuan, J. A hidden state in the turnover of a functioning membrane protein complex. Sci. Adv. 2019, 5, eaau6885. [CrossRef] 
168. Fukuoka, H.; Wada, T.; Kojima, S.; Ishijima, A.; Homma, M. Sodium-dependent dynamic assembly of membrane complexes in sodium-driven flagellar motors. Mol. Microbiol. 2009, 71, 825-835. [CrossRef]

169. Tipping, M.J.; Steel, B.C.; Delalez, N.J.; Berry, R.M.; Armitage, J.P. Quantification of flagellar motor stator dynamics through in vivo proton-motive force control: PMF-dependent motor dynamics. Mol. Microbiol. 2013, 87, 338-347. [CrossRef]

(C) 2019 by the authors. Licensee MDPI, Basel, Switzerland. This article is an open access article distributed under the terms and conditions of the Creative Commons Attribution (CC BY) license (http://creativecommons.org/licenses/by/4.0/). 